\title{
Electrochemically Driven Water-Oxidation Catalysis Beginning with Six Exemplary Cobalt Polyoxometalates: Is It Molecular, Homogeneous Catalysis or Electrode-Bound, Heterogeneous CoOx Catalysis?
}

\author{
Scott J. Folkman, Joaquin Soriano-Lopez, José Ramoń Galan-Mascaros, Richard G. Finke \\ Chemistry Department, Colorado State University, Fort Collins, Colorado 80523, United States \\ Institute of Chemical Research of Catalonia (ICIQ), The Barcelona Institute of Science and Technology (BIST), Av Països \\ Catalans 16, E-43007 Tarragona, Spain \\ * Supporting Information
}

\begin{abstract}
A series of six exemplary cobalt-polyoxometalate (Co-POM) precatalysts have been examined to determine if they are molecular wateroxidation catalysts (WOCatalysts) or if, instead, they actually form heterogeneous, electrode-bound $\mathrm{CoO}_{x}$ as the true WOCatalyst under electrochemically driven water-oxidation catalysis (WOCatalysis) conditions. Specifically, WOCatalysis derived from the following six Co-POMs has been examined at $\mathrm{pH}$ 5.8, 8.0, and 9.0: $\left[\mathrm{Co}_{4}\left(\mathrm{H}_{2} \mathrm{O}\right)_{2}\left(\mathrm{PW}_{9} \mathrm{O}_{34}\right)_{2}\right]^{10-}\left(\mathrm{Co}_{4} \mathrm{P}_{2} \mathrm{~W}_{18}\right)$, $\left[\mathrm{Co}_{9}\left(\mathrm{H}_{2} \mathrm{O}\right)_{6}(\mathrm{OH})_{3}\left(\mathrm{HPO}_{4}\right)_{2}\left(\mathrm{PW}_{9} \mathrm{O}_{34}\right)_{3}\right]^{16-}\left(\mathrm{Co}_{9} \mathrm{P}_{5} \mathrm{~W}_{27}\right), \quad[\beta \beta-$ $\left.\mathrm{Co}_{4}\left(\mathrm{H}_{2} \mathrm{O}\right)_{2}\left(\mathrm{P}_{2} \mathrm{~W}_{15} \mathrm{O}_{56}\right)_{2}\right]^{16-}\left(\mathrm{Co}_{4} \mathrm{P}_{4} \mathrm{~W}_{30}\right),\left[\mathrm{Co}\left(\mathrm{H}_{2} \mathrm{O}\right) \mathrm{PW}_{11} \mathrm{O}_{39}\right]^{5-}\left(\mathrm{CoPW}_{11}\right)$,

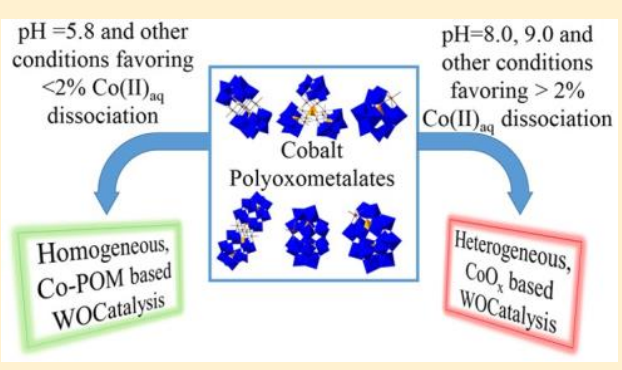
$\left[\alpha_{1}-\mathrm{Co}\left(\mathrm{H}_{2} \mathrm{O}\right) \mathrm{P}_{2} \mathrm{~W}_{17} \mathrm{O}_{61}\right]^{8-}\left(\alpha_{1}-\mathrm{CoP}_{2} \mathrm{~W}_{17}\right)$, and $\left[\alpha_{2}-\mathrm{Co}\left(\mathrm{H}_{2} \mathrm{O}\right) \mathrm{P}_{2} \mathrm{~W}_{17} \mathrm{O}_{61}\right]^{8-}$ $\left(\mathrm{a}_{2}-\mathrm{CoP}_{2} \mathrm{~W}_{17}\right)$. The amount of $\mathrm{Co}(\mathrm{II})_{\mathrm{aq}}$ in $500 \mu \mathrm{M}$ solutions of each Co-POM was measured after $3 \mathrm{~h}$ of aging as well as from $\mathrm{t}=0$ for $\mathrm{pH}=5.8$ and 8.0 by $\mu \mathrm{M}$ sensitive $\mathrm{Co}(\mathrm{II})_{\mathrm{aq}}$-induced ${ }^{31} \mathrm{P}$ NMR line broadening and at $\mathrm{pH}=9.0$ by cathodic stripping. The amount of detectable $\mathrm{Co}(\mathrm{II})_{\mathrm{aq}}$ after $3 \mathrm{~h}$ for the six Co-POMs ranges from $\sim 0.25$ to $\sim 90 \%$ of the total cobalt initially present in the Co-POM. For 12 out of 18 total Co-POM and different $\mathrm{pH}$ cases, the amount $\mathrm{Co}(\mathrm{II})_{\mathrm{aq}}$ detected after $3 \mathrm{~h}$ forms heterogeneous $\mathrm{CoO}_{x}$ able to account for $\geq 100 \%$ of the observed WOCatalysis activity. However, under $0.1 \mathrm{M} \mathrm{NaPi}, \mathrm{pH}$ 5.8 conditions for $\mathrm{CoPW}_{11}$ and $\mathrm{\alpha}_{1}-\mathrm{CoP}_{2} \mathrm{~W}_{17}$ where $\sim 1.5 \%$ and $0.25 \% \mathrm{Co}(\mathrm{III})_{\mathrm{aq}}$ is detectable, the measured $\mathrm{Co}(\mathrm{II})_{\mathrm{aq}}$ cannot account for the observed WOCatalysis. The implication is that these two Co-POMs are primarily molecular, Co-POM-based, WOCatalysts under electrochemically driven, $\mathrm{pH} 5.8$, phosphate-buffer conditions. Even for the single most stable Co-POM, $\mathrm{a}_{1}-\mathrm{CoP}_{2} \mathrm{~W}_{17}, \mathrm{CoO}_{\mathrm{x}}$ is still an estimated $\sim 76 \times$ faster WOCatalyst at $\mathrm{pH}=5.8$ and an estimated $\sim 740 \times$ faster WOCatalyst at $\mathrm{pH}$ $=8$.
\end{abstract}

\section{INTRODUCTION}

Meeting the growing global energy demand requires the development of new technologies and energy-storage schemes. $^{1,2}$ Electrocatalytic water splitting is one widely discussed scheme for generating hydrogen as a renewable fuel. ${ }^{2}$ The bottleneck of the needed electrocatalytic water splitting is the anodic half reaction, catalytic water oxidation. As such, there has been a tremendous interest in, and resultant publication on, the development and screening of water oxidation catalysts (WOCatalysts) (a SciFinder search of "water oxidation" yields 6550 hits, while "water oxidation catalysis" yields 281 references since 2000 and as of March 2018). ${ }^{3-16}$ The identification of the kinetically dominant WOCatalyst-the primary focus of the present study-is directly relevant to the rational development of selective, active, and long-lived WOCatalysts.

Polyoxometalates (POMs), in particular, cobalt-based polyoxometalates (Co-POMs), have attracted huge interest in the WOCatalysis area ${ }^{6,7,9-17}$ since Hill and co-workers initial report focussing on Co-POMs. ${ }^{9}$ POMs are discrete metal oxide compounds that can be readily synthesized on the gram to kilogram or larger scale via self-assembly. POMs are typically composed of high-valent (and therefore oxidatively stable) elements such as $\mathrm{W}(\mathrm{VI}), \mathrm{P}(\mathrm{V}), \mathrm{Mo}(\mathrm{VI})$, and $\mathrm{V}(\mathrm{V})$. Interest in POMs for WOCatalysis comes from the fact that POMs are known to incorporate redox-active metal centers such as cobalt and ruthenium, both of which are active toward WOCatalysis. ${ }^{18-20}$

However, no known Co-POM is $100 \%$ hydrolytically stable over a wide range of $\mathrm{pH}$ values. The few Co-POMs that have had their Co(II) binding constants measured show that those $\mathrm{Co}$ (II) binding constants are in the micromolar range. ${ }^{21,22}$ The micromolar amount of $\mathrm{Co}(\mathrm{II})_{\mathrm{aq}}$ that is leached when the CoPOMs are aged in buffered solutions can then deposit onto anodes during controlled potential WOCatalysis, in turn creating a well-known heterogeneous $\mathrm{CoO}_{\mathrm{x}}$ film ${ }^{8}$ as the active, electrochemically driven WOCatalyst. Such $\mathrm{CoO}_{x}$ films have 
Scheme 1. List of Six Alternative Hypotheses for the Kinetically Dominant WOCatalyst under a Specific Set of Conditions

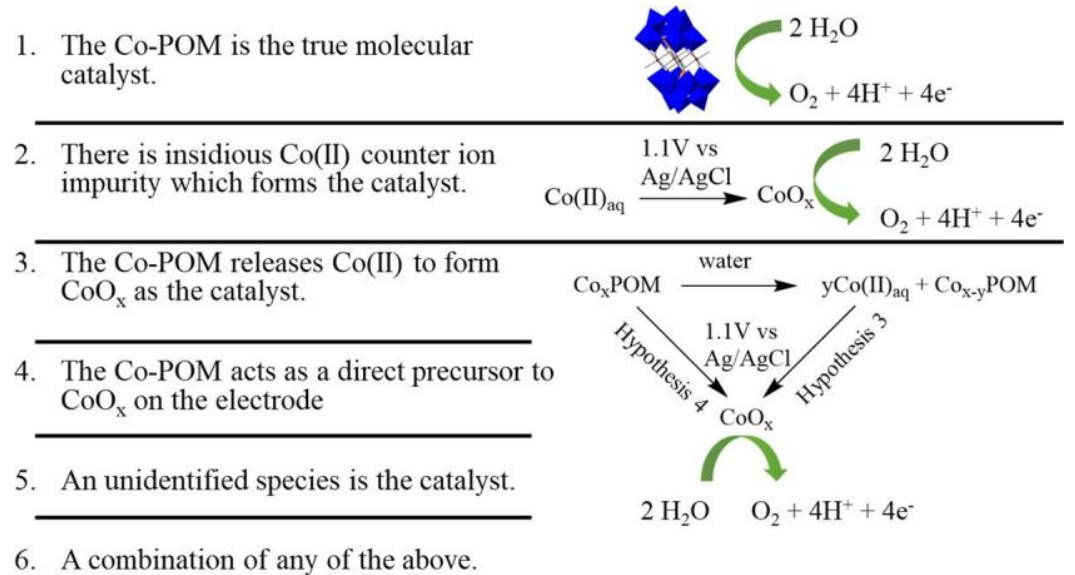

been shown to account quantitatively for all of the observed electrocatalytically driven WOCatalysis current in the case of $\left[\mathrm{Co}_{4}\left(\mathrm{H}_{2} \mathrm{O}\right)_{2}\left(\mathrm{PW}_{9} \mathrm{O}_{34}\right)_{2}\right]^{10-}\left(\mathrm{Co}_{4} \mathrm{P}_{2} \mathrm{~W}_{18}\right)$ in $0.1 \mathrm{M}$ sodium phosphate $\mathrm{pH}=8.0$ buffer and also for $\left[\mathrm{Co}_{4}\left(\mathrm{H}_{2} \mathrm{O}\right)_{2}\left(\mathrm{VW}_{9} \mathrm{O}_{34}\right)_{2}\right]^{10-}\left(\mathrm{Co}_{4} \mathrm{~V}_{2} \mathrm{~W}_{18}\right)$ in $0.1 \mathrm{M}$ sodium phosphate $\mathrm{pH}=8.0$ and 5.8 buffers, as well as $0.1 \mathrm{M}$ sodium borate $\mathrm{pH}=9.0$ buffer. $^{21,23-27}$

Our 2014 review entitled "Distinguishing Homogeneous from Heterogeneous Water Oxidation Catalysis When Beginning with Polyoxometalates" highlights the issues in, as well as preferred techniques for, distinguishing between homogeneous and heterogeneous WOCatalysis when beginning with POMs. ${ }^{25}$ The main findings of that review include that (i) multiple complementary methods are necessary en route to determining the Co-POM speciation, stability, and ultimately the identity of the true WOCatalyst; ${ }^{17,25,27}$ (ii) the amount of redox active metal such as $\mathrm{Co}$ (II) $)_{\text {aq }}$ that is leached into solution (or present as a countercation impurity, as discovered herein) needs to be determined quantitatively; (iii) one needs to perform control experiments examining authentic heterogeneous $\mathrm{CoO}_{\mathrm{x}}$ self-assembled from $\mathrm{Co}(\mathrm{II})_{\mathrm{aq}}$ under the catalytic reaction conditions; (iv) the contribution to catalysis of heterogeneous $\mathrm{CoO}_{x}$ or other metal oxides must then be quantified; and overall, (v) the stability of each POM is dependent upon the unique POM structure, the structural metals (e.g., W, Mo), the heteroatoms (e.g., P, Si, others), the redox-active metal (e.g., $\mathrm{Co}, \mathrm{Ru}$ ), and the reaction conditions, notably the $\mathrm{pH}$, buffer type, and buffer concentration. Additionally, the true WOCatalyst is often dependent on the method of oxidation (e.g., chemical, photochemical, or electrochemical).

Unfortunately, of the many studies using Co-POMs or other M-POMs ( $\mathrm{M}$ = catalytically active metal) employed as water oxidation precatalysts, very few publications conduct the necessary experiments to provide compelling evidence for or against homogeneous molecular vs heterogeneous metal oxide WOCatalysis. There are important exceptions, ${ }^{7,13,17,23,27,28}$ that are discussed where relevant in the sections that follow. Other studies that use POMs for WOCatalysis, but which are not specifically treated in the main text of the present contribution, are summarized for the interested reader in Table S1 of the Supporting Information. In short, if and when Co-POMs can serve as molecular WOCatalysts has remained controversial.

$\left[\mathrm{Co}_{4}\left(\mathrm{H}_{2} \mathrm{O}\right)_{2}\left(\mathrm{PW}_{9} \mathrm{O}_{34}\right)_{2}\right]^{10-}$ : A Prototype Co-POM WOPrecatalyst. The early prototype of a Co-POM WOCatalysis

precatalyst system is $\left[\mathrm{Co}_{4}\left(\mathrm{H}_{2} \mathrm{O}\right)_{2}\left(\mathrm{PW}_{9} \mathrm{O}_{34}\right)_{2}\right]^{10-}\left(\mathrm{Co}_{4} \mathrm{P}_{2} \mathrm{~W}_{18}\right)$ in $0.1 \mathrm{M}$ sodium phosphate $\mathrm{pH}=8.0 .{ }^{9,23,24}$ Previous work has shown that, after $3 \mathrm{~h}$ of aging in $0.1 \mathrm{M} \mathrm{NaPi}$ solution, $500 \mu \mathrm{M}$ $\left[\mathrm{Co}_{4}\left(\mathrm{H}_{2} \mathrm{O}\right)_{2}\left(\mathrm{PW}_{9} \mathrm{O}_{34}\right)_{2}\right]^{10-}$ dissociates a mere $58 \mu \mathrm{M} \mathrm{Co}(\mathrm{II})$ corresponding to just $4.3 \%$ decomposition (assuming the loss of a single $\mathrm{Co}(\mathrm{II})$ from the parent Co-POM). ${ }^{23}$ That $58 \mu \mathrm{M}$ $\mathrm{Co}(\mathrm{II})_{\mathrm{aq}}$ forms a highly catalytically active heterogeneous $\mathrm{CoO}_{x}$ films on tin-doped indium oxide (ITO) or glassy carbon electrodes under constant potential electrolysis. ${ }^{23}$ The resultant $\mathrm{CoO}_{\mathrm{x}}$ film accounts for $100 \pm 12 \%$ of the WOCatalysis current under the $0.1 \mathrm{M} \mathrm{NaPi}$ buffer and electrochemically driven WOCatalysis conditions. ${ }^{23}$

However, and in experiments designed to deliberately favor molecular WOCatalysis by $\mathrm{Co}_{4} \mathrm{P}_{2} \mathrm{~W}_{18}$, when $2.5 \mu \mathrm{M}$ $\left[\mathrm{Co}_{4}\left(\mathrm{H}_{2} \mathrm{O}\right)_{2}\left(\mathrm{PW}_{9} \mathrm{O}_{34}\right)_{2}\right]^{10-}$ is dissolved in $\mathrm{NaPi} \mathrm{pH} 8.0$ or 5.8 with $\geq 600 \mathrm{mV}$ overpotential, the detected amount of Co(II) cannot account for the observed WOCatalysis current under the stated conditions-evidence that $\mathrm{CoO}_{\mathrm{x}}$ is not the dominant catalyst under those only modestly different conditions. ${ }^{24}$ The now classic $\mathrm{Co}_{4} \mathrm{P}_{2} \mathrm{~W}_{18}$ system is a good example of how seemingly small changes in conditions can alter the kinetically dominant form of the Co-POM-derived WOCatalyst.

A second important example of a system where the formation of $\mathrm{CoO}_{\mathrm{x}}$ from a Co-POM has been carefully examined is a 2012 Inorg. Chem. publication ${ }^{13}$ in which the Co$\mathrm{POM}\left[\mathrm{Co}_{9}\left(\mathrm{H}_{2} \mathrm{O}\right)_{6}(\mathrm{OH})_{3}\left(\mathrm{HPO}_{4}\right)_{2}\left(\mathrm{PW}_{9} \mathrm{O}_{34}\right)_{3}\right]^{16-}$ $\left(\mathrm{Co}_{9} \mathrm{P}_{5} \mathrm{~W}_{27}\right)$ was shown to form $\mathrm{CoO}_{\mathrm{x}}$ under controlled potential electrolysis. ${ }^{13}$ Addition of bipyridine to starting solutions of $\mathrm{Co}_{9} \mathrm{P}_{5} \mathrm{~W}_{27}$ chelates leached $\mathrm{Co}(\mathrm{III})_{\mathrm{aq}}$ and prevents the formation of $\mathrm{CoO}_{\mathrm{x}}$ under electrocatalytic conditions. ${ }^{13}$ WOCatalysis current was still observed in the presence of bipyridine, consistent with molecular $\mathrm{Co}_{9} \mathrm{P}_{5} \mathrm{~W}_{27}$ being a true, electrochemically driven, homogeneous WOCatalyst, albeit one with only $\sim 2 \%$ of the WOCatalysis current of $\mathrm{CoO}_{x}$ formed in the absence of bipyridine. ${ }^{13}$ This is another, important conclusion from prior studies: when molecular WOCatalysis from Co-POMs is seen, that activity (at least to date) is often only $1 / 2-1 / 11$ th that of the activity of $\mathrm{CoO}_{x}$ examined under identical conditions. ${ }^{23-27}$

Identifying the kinetically dominant WOCatalyst from a molecular precatalyst is often difficult, ${ }^{9,13,23-27}$ especially in cases where as much as $>95-99 \%$ of the initial POM remains intact under the reaction conditions. Only the scientific method of multiple alternative hypotheses is able to provide 

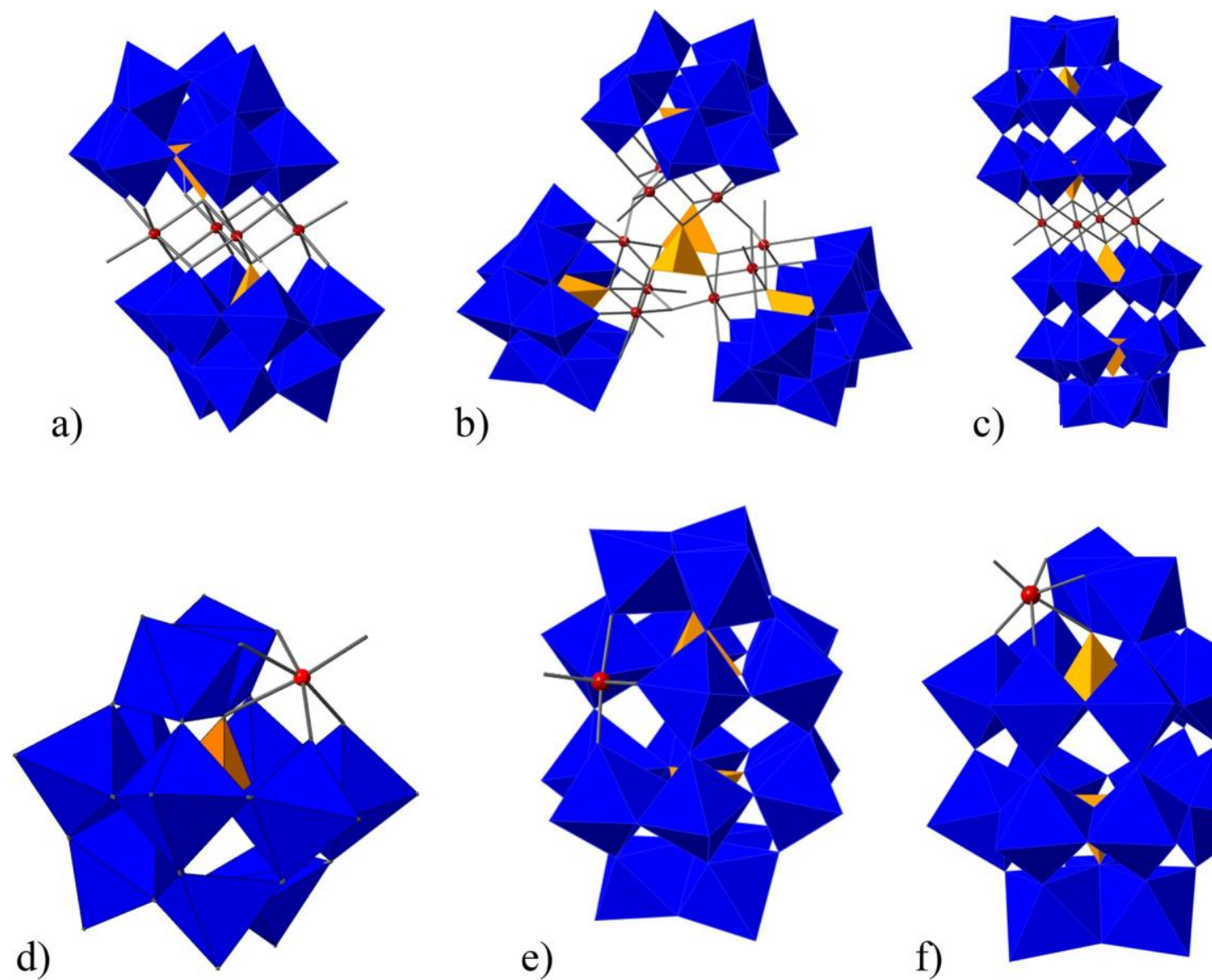

e)

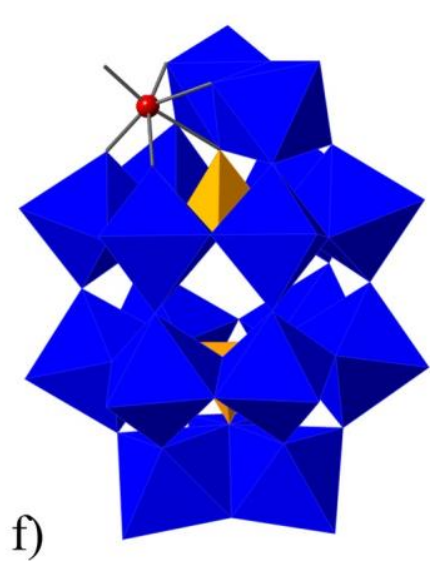

Figure 1. Polyhedral representations of the structure of the Co-POMs: (a) $\mathrm{Co}_{4} \mathrm{P}_{2} \mathrm{~W}_{18}$; (b) $\mathrm{Co}_{9} \mathrm{P}_{5} \mathrm{~W}_{27}$; (c) $\mathrm{Co}_{4} \mathrm{P}_{4} \mathrm{~W}_{30}$; (d) $\mathrm{CoPW}_{11}$; (e) $\mathrm{\alpha}_{1}$ $\mathrm{CoP}_{2} \mathrm{~W}_{17}$; (f) $\mathrm{a}_{2}-\mathrm{CoP}_{2} \mathrm{~W}_{17}$. Blue octahedra represent $\mathrm{WO}_{6}$, orange tetrahedra represent $\mathrm{PO}_{4}$, and red spheres are Co(II). The coordination site on the $\mathrm{Co}$ atoms typically binds $\mathrm{H}_{2} \mathrm{O}$ and is where WOCatalysis is generally postulated to occur if the Co-POMs are indeed homogeneous, molecular WOCatalysts.

convincing, compelling evidence for the kinetically dominant, "true" WOCatalyst. ${ }^{25,29}$ Scheme 1 presents six alternative hypotheses for the true catalyst when beginning with molecular, M-POM precatalysts $(\mathrm{M}=$ metal such as $\mathrm{Co}$, $\mathrm{Ru}$ ). The first hypothesis is that the precatalyst remains intact and is a homogeneous WOCatalyst, as the evidence strongly supports for the $\mathrm{Ru}_{4}-\mathrm{POM}, \mathrm{Cs}_{10}\left[\mathrm{Ru}_{4}(\mu-\mathrm{O})_{4}(\mu-\right.$ $\left.\mathrm{OH})_{2}\left(\mathrm{H}_{2} \mathrm{O}\right)_{4}\left(\mathrm{Y}-\mathrm{SiW}_{10} \mathrm{O}_{36}\right)_{2}\right]$. $^{7}$ A second hypothesis is that there is insidious $\mathrm{Co}$ (II) (e.g., present as a countercation from the synthesis) which then forms heterogeneous $\mathrm{CoO}_{x}$ as the dominant catalyst; $\mathrm{Co}_{4} \mathrm{O}_{4}$ cubanes being a case in point. ${ }^{28} \mathrm{~A}$ third hypothesis is that the precatalyst (Co-POM) is hydrolytically unstable and leaches $\mathrm{Co}(\mathrm{II})_{\mathrm{aq}}$ into solution which then forms heterogeneous $\mathrm{CoO}_{x}$ as the WOCatalyst. Such leaching of $\mathrm{Co}(\mathrm{II})_{\mathrm{aq}}$ and then the formation of $\mathrm{CoO}_{\mathrm{x}}$ is observed for both $\mathrm{Co}_{4} \mathrm{P}_{2} \mathrm{~W}_{18}$ and $\mathrm{Co}_{4} \mathrm{~V}_{2} \mathrm{~W}_{18}$, as already noted. $^{23,27}$ A fourth alternative hypothesis is that electrodebound Co-POM serves as a direct precursor to $\mathrm{CoO}_{x}$ on the electrode without yielding solution-deteactable $\mathrm{Co}(\mathrm{II})_{\mathrm{aq}}$. A fifth, quite reasonable hypothesis is that a fragment of the original Co-POM, POM-stabilized $\mathrm{CoO}_{x}$ nanoparticles, or perhaps some other presently unidentified species is actually the true catalyst. Lastly, it is always possible that more than one of the five hypotheses listed might be occurring simultaneously, as was the case with the formation of $\mathrm{CoO}_{x}$ from $\mathrm{Co}_{9} \mathrm{P}_{5} \mathrm{~W}_{27}$ where WOCatalysis activity is still observed when
$\mathrm{Co}(\mathrm{II})_{\mathrm{aq}_{3}}$ is removed by chelation with bipyridine (vide supra).

Focus of the Present Studies. The focus of the current study is to establish the stability, speciation, and kinetically dominant WOCatalysts from the six exemplary Co-POMs shown in Figure 1. Three buffer and $\mathrm{pH} \mathrm{5.8,} \mathrm{8.0,} \mathrm{and} \mathrm{9.0}$ conditions have been selected because they are the most common buffers in the Co-POM WOCatalysis literature, and because they examine a case favoring Co-POM stability ( $\mathrm{pH}=$ 5.8) and a case at higher $\mathrm{pH}$ where the thermodynamics of water oxidation are favored in the same buffer $(\mathrm{pH}=8.0)$. These exemplary Co-POMs allow examination of the observed WOCatalysis as a function of varied $\mathrm{Co}(\mathrm{II})$ coordination environments (e.g., single vs multiple redox centers) and as a function of different $\mathrm{Co}$ (II) binding sites. The six Co-POMs chosen for study are the prototype $\left[\mathrm{Co}_{4}\left(\mathrm{H}_{2} \mathrm{O}\right)_{2}\left(\mathrm{PW}_{9} \mathrm{O}_{34}\right)_{2}\right]^{10-}$ $\left(\mathrm{Co}_{4} \mathrm{P}_{2} \mathrm{~W}_{18}\right)$ (because it is relatively well-studied ${ }^{9,17,23,24}$ and, therefore, serves as a benchmark system for controls and comparisons); $\left[\mathrm{Co}_{9}\left(\mathrm{H}_{2} \mathrm{O}\right)_{6}(\mathrm{OH})_{3}\left(\mathrm{HPO}_{4}\right)_{2}\left(\mathrm{PW}_{9} \mathrm{O}_{34}\right)_{3}\right]^{16-}$ $\left(\mathrm{Co}_{9} \mathrm{P}_{5} \mathrm{~W}_{27}\right)$, which has been reported to exhibit homogeneous WOCatalysis under electrocatalytically driven conditions (vida supra) and which shows very interesting, high WOCatalysis activity $\left(\eta=189 \mathrm{mV}\right.$ at $\left.1 \mathrm{~mA} / \mathrm{cm}^{2}\right)$ as an insoluble $\mathrm{Ba}^{2+}$ salt embedded within amorphous carbon paste $;^{13,30-33}$ and $[\beta \beta$ $\left.\mathrm{Co}_{4}\left(\mathrm{H}_{2} \mathrm{O}\right)_{2}\left(\mathrm{P}_{2} \mathrm{~W}_{15} \mathrm{O}_{56}\right)_{2}\right]^{16-}\left(\mathrm{Co}_{4} \mathrm{P}_{4} \mathrm{~W}_{30}\right)$, selected because its Co centers are isostructural with $\mathrm{Co}_{4} \mathrm{P}_{2} \mathrm{~W}_{18}$, yet this Co-POM was previously reported, surprisingly, as not exhibiting 
WOCatalysis using $\mathrm{Ru}(\mathrm{bpy}) 3^{3+}$ as the oxidant ${ }^{9,34,35}$ even though its close congener, $\mathrm{Co}_{4} \mathrm{P}_{2} \mathrm{~W}_{18}$, does. ${ }^{9}$ The final three of the six Co-POMs are single Co-containing $\left[\mathrm{Co}\left(\mathrm{H}_{2} \mathrm{O}\right)\right.$ $\left.\mathrm{PW}_{11} \mathrm{O}_{39}\right]^{5-}\left(\mathrm{CoPW}_{11}\right)$, which has been shown to form $\mathrm{CoO}_{\mathrm{x}}$ under electrocatalytic conditions in $\mathrm{pH} 7$ phosphate buffer solutions, ${ }^{9,36-40}$ yet is reported to not exhibit WOCatalysis activity using $\mathrm{Ru}(\mathrm{bpy})_{3}{ }^{3+}$ as the chemical oxidant; ${ }^{9}$ and $\left[\alpha_{1}-\right.$ $\left.\mathrm{Co}\left(\mathrm{H}_{2} \mathrm{O}\right) \mathrm{P}_{2} \mathrm{~W}_{17} \mathrm{O}_{61}\right]^{8-}\left(\alpha_{1}-\mathrm{CoP}_{2} \mathrm{~W}_{17}\right)$ and $\left[\mathrm{a}_{2}-\mathrm{Co}\left(\mathrm{H}_{2} \mathrm{O}\right)-\right.$ $\left.\mathrm{P}_{2} \mathrm{~W}_{17} \mathrm{O}_{61}\right]^{8-}\left(\mathrm{a}_{2}-\mathrm{CoP}_{2} \mathrm{~W}_{17}\right)$, two isomeric, single-cobalt Co$\mathrm{POMs}^{21,22,41,42}$ chosen because they have literature precedent $^{43}$ as WOPrecatalysts and because they therefore allow insights into the role of different $\mathrm{Co}$ (II)-to-POM binding sites and structures on the resultant WOCatalysis and kinetically dominant WOCatalyst.

Meriting mention here is that the dicobalt(IV)- $\mu$-oxo dimer of $\alpha_{2}-\mathrm{CoP}_{2} \mathrm{~W}_{17}\left[\left(\alpha_{2^{-}} \mathrm{Co}^{\mathrm{IV}} \mathrm{P}_{2} \mathrm{~W}_{17} \mathrm{O}_{61}\right)_{2} \mathrm{O}\right]^{14-}$ (formed from $\boldsymbol{\alpha}_{2^{-}}$ $\mathrm{CoP}_{2} \mathrm{~W}_{17}$ using ozone as the oxidant and as an inner-sphere oxo transfer reagent) has been shown to generate $\mathrm{O}_{2}$ from water in $\sim 95 \%$ yield, according to eq $1 .{ }^{44}$ However, it is not currently known if $\left[\left(\alpha_{2}-\mathrm{Co}^{\mathrm{IV}} \mathrm{P}_{2} \mathrm{~W}_{17} \mathrm{O}_{61}\right)_{2} \mathrm{O}\right]^{14-}$ can form from $\left[\alpha_{2}-\mathrm{Co}^{\mathrm{II}}\left(\mathrm{H}_{2} \mathrm{O}\right) \mathrm{P}_{2} \mathrm{~W}_{17} \mathrm{O}_{61}\right]^{8-}$ under electrochemical oxidation. If formation of the $\mu$-oxo dimer did occur, then one might expect to observe homogeneous WOCatalysis from $\alpha_{2^{-}}$ $\mathrm{CoP}_{2} \mathrm{~W}_{17}$.

$$
\begin{aligned}
& {\left[\left(\alpha_{2}-\mathrm{Co}^{\mathrm{IV}} \mathrm{P}_{2} \mathrm{~W}_{17} \mathrm{O}_{61}\right)_{2} \mathrm{O}\right]^{14-}+3 \mathrm{H}_{2} \mathrm{O}} \\
& \quad \rightarrow 2\left[\alpha_{2}-\mathrm{Co}^{\mathrm{II}}\left(\mathrm{OH}_{2}\right) \mathrm{P}_{2} \mathrm{~W}_{17} \mathrm{O}_{61}\right]^{8-}+\mathrm{O}_{2}+2 \mathrm{H}^{+}
\end{aligned}
$$

Choice of Reaction Conditions and Key Experimental Methodologies. The conditions chosen to examine the CoPOMs in Figure 1 include sodium phosphate buffer $(\mathrm{NaPi})$ at both $\mathrm{pH} 5.8$ (favoring the stability of the Co-POMs) and 8.0 (favoring the thermodynamics of water oxidation). We also used sodium borate buffer $(\mathrm{NaB})$ at $\mathrm{pH} 9.0$ to compare the effect of buffer since Co-POMs tend to be more stable in $\mathrm{NaB}$ buffer $^{17}$ and because NaPi can, at least in principle, drive the decomposition of Co-POMs due to the formation of insoluble $\mathrm{Co}_{3}\left(\mathrm{PO}_{4}\right)_{2} \quad\left(\mathrm{~K}_{\mathrm{sp}} \approx 10^{-35}\right) .{ }^{45}$ Similar to our previous publications, we aged the Co-POMs in each respective buffer for $3 \mathrm{~h}$ as a relatively minimal solution lifetime. ${ }^{23,27}$

Note that $3 \mathrm{~h}$ aging is at most a minimum test of the stability of the Co-POMs because any truly useful WOCatalyst will need to be active for perhaps $10^{3-4} \mathrm{~h}$ or more of WOC (thereby for lifetimes that may approach an estimated $>10^{9}$ total turnovers), ${ }^{27}$ so that even if the turnover frequency was among the highest reported for a Co-POM (i.e., $200 \mathrm{~s}^{-1}$ ), ${ }^{16}$ then any molecular Co-POM WOCatalyst would still need to be active for $>140 \mathrm{~h}$-meaning that our $3 \mathrm{~h}$ test is only $2 \%$ of the required catalytic lifetime. However, and importantly, we also examine the amount of $\mathrm{Co}(\mathrm{II})_{\mathrm{aq}}$ formation at $\mathrm{t} \approx 0$ and as a function of time by ${ }^{31} \mathrm{P}$ NMR in what follows.

In order to quantify the amount of $\mathrm{Co}$ (II) that dissociates from the complexes, $\mathrm{Co}(\mathrm{II})_{\mathrm{aq}}$-induced ${ }^{31} \mathrm{P}$ NMR line broadening of the $\mathrm{P}$ atom in the phosphate buffer is used. ${ }^{27,28,46-48}$ Adsorptive cathodic stripping is then used in what follows as a secondary method to quantify the $\mathrm{Co}(\mathrm{II})_{\mathrm{aq}}$ in $\mathrm{NaPi}$ and the primary method to quantify the $\mathrm{Co}(\mathrm{II})_{\mathrm{aq}}$ leached from the CoPOMs in $\mathrm{NaB} .^{23,27,49}$ Once the stability of each Co-POM was established under a given set of conditions, controlled potential electrolysis was conducted at $1.1 \mathrm{~V}$ vs $\mathrm{Ag} / \mathrm{AgCl}$ in the aged CoPOM solutions and the amount of $\mathrm{O}_{2}$ produced was compared with the amount of $\mathrm{O}_{2}$ produced from an equivalent amount of $\mathrm{Co}(\mathrm{II})_{\mathrm{aq}}$ that was detected. Note that $1.1 \mathrm{~V}$ was chosen because glassy carbon is known to oxidize to $\mathrm{CO}_{2}$ at $\geq 1.2 \mathrm{~V}$ vs $\mathrm{Ag} / \mathrm{AgCl}{ }^{28}$ As such, each buffer condition has a different applied over potential of $\eta=410 \mathrm{mV}$ at $\mathrm{pH}=5.8, \eta=540 \mathrm{mV}$ at $\mathrm{pH}=8.0$, and $\eta=600 \mathrm{mV}$ at $\mathrm{pH}=9.0$. Next, controlled potential electrolysis is conducted to allow film accumulation, followed by cyclic voltammetry in the original Co-POM solution. The electrodes were then removed and rinsed followed by cyclic voltammetry of the working electrode in a fresh, buffer-only solution, thereby obtaining the CV of any deposited film. The deposited films in what follows are also characterized by scanning electron microscopy (SEM) and Xray photoemission spectroscopy (XPS). The sum of these experiments is then used collectively to provide evidence for the kinetically dominant WOCatalyst under a stated set of conditions.

Finally, a historical note is perhaps of some interest: we never started out to pursue the "what is the true catalyst?" question in the WOCatalysis area and despite our background with this question in the area of hydrogenation catalysis with low-valent metal nanoparticles. ${ }^{50}$ Instead, this key question quickly found us in the area of Co-POMs as WOPrecatalysts. Our first experiments used $\mathrm{Co}_{4} \mathrm{P}_{2} \mathrm{~W}_{18}$ as a WOPrecatalyst in our OPV-driven WOC half-cell, ${ }^{11}$ the Co-POM $\mathrm{Co}_{4} \mathrm{P}_{2} \mathrm{~W}_{18}$ being "close to our intellectual hearts" since we discovered the rational synthesis of and $\mathrm{Co}_{4} \mathrm{P}_{2} \mathrm{~W}_{18}, \mathrm{Co}_{4} \mathrm{P}_{4} \mathrm{~W}_{30}$, and the other members of this class of $\mathrm{M}_{4}$-containing POMs in $1981 .{ }^{52}$ The very first experiments with $\mathrm{CO}_{4} \mathrm{P}_{2} \mathrm{~W}_{18}$ provided evidence that an electrode-bound catalyst, the same color as Nocera's $\mathrm{CoO}_{\mathrm{x}} / \mathrm{Pi}$ catalyst $^{8}$ that we had been examining, had formed on the ITO anode from the $\mathrm{CO}_{4} \mathrm{P}_{2} \mathrm{~W}_{18}$ precatalyst. ${ }^{23}$ The findings quickly followed that the $\mathrm{Co}_{4} \mathrm{P}_{2} \mathrm{~W}_{18}$ POM leached $\mathrm{Co}$ (II) into solution from just $4.3 \%$ decomposition over $3 \mathrm{~h}$, and that the resultant $58 \mu \mathrm{m} \mathrm{Co}$ (II) formed electrode-bound $\mathrm{CoO}_{\mathrm{x}}$ that accounted for $100 \pm 12 \%$ of the observed, electrochemically driven, WOCatalysis current. ${ }^{23} \mathrm{~A}$ similar situation occurred for the V-based congener, $\mathrm{Co}_{4} \mathrm{~V}_{2} \mathrm{~W}_{18}$ : we were intrigued by the claim of $100 \%$ hydrolytic stability, and 200-fold higher catalytic activity compared to the P-congener. ${ }^{16}$ Yet when we prepared $\mathrm{Co}_{4} \mathrm{~V}_{2} \mathrm{~W}_{18}$ by the literature route and tried to purify it to the ${ }^{51} \mathrm{~V}$ NMR resonance assigned in the literature to $\mathrm{Co}_{4} \mathrm{~V}_{2} \mathrm{~W}_{18}$, the resultant, different color POM contained only $\sim 1$ Co per $\mathrm{V}_{2} \mathrm{~W}_{18} \mathrm{O}_{68}{ }^{18-}$ unit-yet had the same ${ }^{51} \mathrm{~V}$ NMR resonance ascribed to " $\mathrm{Co}_{4} \mathrm{~V}_{2} \mathrm{~W}_{18}$ ". ${ }^{53}$ The $100 \%$ hydrolytic instability of $\mathrm{Co}_{4} \mathrm{~V}_{2} \mathrm{~W}_{18}$, its decomposition to $\mathrm{Co}$ (II) and formation of electrode-bound $\mathrm{CoO}_{x} / \mathrm{Pi}$ that carries $100 \%$ of the observed WOC within experimental error, as well as assignment of the observed ${ }^{51} \mathrm{~V}$ NMR resonance to the impurity $\mathrm{V}_{2} \mathrm{~W}_{4} \mathrm{Q}_{9}{ }^{6-}$ followed after considerable effort. ${ }^{27,53}$ In short, the "what is the true catalyst?" question raised its omnipresent head each and every time we tried to build off the literature of Co-POMs as WO(Pre)Catalysts. That observation is, actually, not surprising, at least in hindsight: the identity of the true catalyst in any and all catalytic reactions is an important, often overlooked, typically challenging, critical question in catalysis. Reflection makes the latter claim obvious once one realizes that all catalytic properties of interest derive from the precise composition and nature of the actual catalyst, including the: catalytic activity, selectivity, lifetime, poisoning, reisolation, and catalyst regeneration. The "what is the catalyst?" question, and the associated "Is it homogeneous or heterogeneous catalysis?" question, had not been fully raised nor critically addressed for cobalt or other POM-based WOCatalysts before our 2011 study that has (as of July 2018) over 246 citations. $^{23}$ The 
present work brings to completion our studies of the kinetically dominant, "true" catalyst(s) derived from exemplary Co-POMs in buffer solutions under electrochemically driven and the other stated, specific WOCatalysis conditions-conditions that matter greatly, vide infra. It is hoped that the WOCatalysis community can use methods and approach herein to provide evidence for the kinetically dominant WOCatalyst as a critical part of their own WOCatalysis studies.

\section{EXPERIMENTAL SECTION}

General Considerations. All reagents used were the highest purity available and were used without further purification. Water (18 $\mathrm{M} \Omega$ ) was obtained from an in house Barnstead Nanopure filtration system. FT-IR were collected using a ThermoScientific Nicolet iS50 FT-IR spectrometer in transmission mode using $\mathrm{KBr}$ pellets containing approximately $2 \mathrm{wt} \%$ of the analyte. Thermogravimetric analysis (TGA) was performed using a TA Instruments TGA 2950 with a $5{ }^{\circ} \mathrm{C} / \mathrm{min}$ ramp rate to $500^{\circ} \mathrm{C}$ on a platinum sample pan. TGA was used to determine the waters of hydration because water is the only volatile component of the Co-POMs at $\leq 500{ }^{\circ} \mathrm{C}$. ${ }^{31} \mathrm{P}$ NMR was collected using either an Agilent (Varian) $400 \mathrm{MHz}$ NMR or an Agilent Inova $500 \mathrm{MHz} \mathrm{NMR}$; the spectral ranges and pulse sequences were optimized for the resonance of the ${ }^{31} \mathrm{P}$ atom of interest. Elemental analyses were obtained from Galbraith Laboratories in Knoxville, TN.

Electrochemically driven WOCatalysis experiments were conducted in $0.1 \mathrm{M}$ sodium phosphate buffer $(\mathrm{NaPi})$ either at $\mathrm{pH} 5.8$ or 8.0 or in $0.1 \mathrm{M}$ sodium borate $(\mathrm{NaB}) \mathrm{pH} 9.0 .^{54}$ All stability, electrochemistry, and WOCatalysis experiments were conducted with a $500 \mu \mathrm{M}$ Co-POM concentration, chosen because the stability of the complexes can be difficult to quantify, and hence, employing this higher, $500 \mu \mathrm{M}$ concentration facilitates detection of decomposition byproducts by ${ }^{31} \mathrm{P}$ NMR, for example (vide infra).

All of the electrochemistry was performed using a $\mathrm{CH}$ Instruments CHI630D with a three-electrode setup. All potentials are referenced to $\mathrm{Ag} / \mathrm{AgCl}$, with a platinum wire as the counter electrode and glassy carbon either 1.0 or $0.071 \mathrm{~cm}^{2}$ as the working electrode. SEM was conducted on a JEOL JSM-6500F microscope with magnification from 1000 to 20000. XPS was conducted on a PE-5800 X-ray photoelectron spectrometer; full scans were collected on deposited films as well as high-resolution scans for individual elements.

Syntheses of the Co-POMs were conducted according to literature methods and characterized via FT-IR, ${ }^{31} \mathrm{P}$ NMR, TGA, and elemental analysis. The procedures followed and resulting characterization data are presented in the Supporting Information for the interested reader (Figures S1-S8). ${ }^{913,21,23,30,31,34-43,52}$ Characterization of the CoPOMs was consistent with prior literature and are isomerically pure samples, with the exception of $\mathrm{K}_{8}\left[\alpha_{1}-\mathrm{Co}\left(\mathrm{H}_{2} \mathrm{O}\right) \mathrm{P}_{2} \mathrm{~W}_{17} \mathrm{O}_{61}\right]$, which contains a presently inseparable $5 \%$ impurity of the isomeric $\mathrm{K}_{8}\left[\alpha_{2}-\right.$ $\left.\mathrm{Co}\left(\mathrm{H}_{2} \mathrm{O}\right) \mathrm{P}_{2} \mathrm{~W}_{17} \mathrm{O}_{61}\right]$.

Stability of the Co-POMs in Buffered Solutions. Stability of the CoPOMs Determined by Co(II)-Induced ${ }^{31} \mathrm{P}$ NMR Line Broadening. The well-established method of $\mathrm{Co}(\mathrm{II})_{\mathrm{aq}}$-induced ${ }^{31} \mathrm{P}$ NMR line broadening of the sodium phosphate buffer, first observed by Klanberg and Dodgen ${ }^{46}$ and used later by Nocera and others to quantify aqueous $\mathrm{Co}$ (II) leached out of $\mathrm{CoO}_{\mathrm{x}}$ film or molecular $\mathrm{Co}$ complexes, ${ }^{27,28,47,48}$ was used to detect the amount of $\mathrm{Co}(\mathrm{II})_{\mathrm{aq}}$ present in NaPi-buffered solutions for each Co-POM. This ${ }^{31} \mathrm{P}$ NMR technique is powerful because it is selective toward $\mathrm{Co}(\mathrm{II})_{\mathrm{aq}}$ (i.e., and insensitive to $\mathrm{Co}(\mathrm{II})$ within a Co-POM) while also having a detection limit of $\sim 2 \mu \mathrm{M} \mathrm{Co}$ (II) ${ }_{\mathrm{aq}}{ }^{26}$ Further precedent for this ${ }^{31} \mathrm{P}$ NMR methodology is its recent use to quantify the amount of $\mathrm{Co}$ (II) leached from $\left[\mathrm{Co}_{4} \mathrm{~V}_{2} \mathrm{~W}_{18} \mathrm{O}_{68}\right]^{10-}$ as well as $\left[\mathrm{Co}_{4} \mathrm{P}_{2} \mathrm{~W}_{18} \mathrm{O}_{68}\right]^{10-}$, results which demonstrate that the ${ }^{31} \mathrm{P}$ method agrees with cathodic stripping determinations of $\mathrm{Co}$ (II) to within $\pm 5 \%$ for both $\left[\mathrm{Co}_{4} \mathrm{~V}_{2} \mathrm{~W}_{18} \mathrm{O}_{68}\right]^{10-}$ and $\left[\mathrm{Co}_{4} \mathrm{P}_{2} \mathrm{~W}_{18} \mathrm{O}_{68}\right]^{10-}$ in $0.1 \mathrm{M} \mathrm{NaPi} \mathrm{pH}=8.0 .^{27}$

We followed the same general procedure outlined in our 2017 paper $^{27}$ for the ${ }^{31} \mathrm{P}$ NMR determinations of Co(II) $)_{\mathrm{aq}}$, except the CoPOM concentrations employed herein are $500 \mu \mathrm{M}$. (The lower concentration of $5 \mu \mathrm{M}$ Co-POM used in our 2016 paper was chosen because $\left[\mathrm{Co}_{4} \mathrm{~V}_{2} \mathrm{~W}_{18} \mathrm{O}_{68}\right]^{10-}$ decomposes $100 \%$, resulting in $\mathrm{Co}(\mathrm{II})_{\mathrm{aq}}$ concentrations too high to measure reliably at more than $5 \mu \mathrm{M}$ of that particular Co-POM). First, a calibration curve was developed using $\mathrm{Co}\left(\mathrm{NO}_{3}\right)_{2}$ as an authentic source of $\mathrm{Co}^{2+}{ }_{\mathrm{aq}}$ for the line broadening experiments in both $\mathrm{pH} 5.8$ and $8.0 \mathrm{NaPi}$ (as $100 \mathrm{mM}$ solutions in $25 \% \mathrm{D}_{2} \mathrm{O}$, Figure $\mathrm{S} 9$ in the Supporting Information). Next, the appropriate amount of Co-POM was weighed in a 1 dram vial. To prepare $2 \mathrm{~mL}$ of a $500 \mu \mathrm{M}$ solution, $1 \mu \mathrm{mol}$ of each POM is required; therefore the following masses of each indicated Co-POM were used: $\mathrm{Co}_{9} \mathrm{P}_{5} \mathrm{~W}_{27}, 8.97 \mathrm{mg} ; \mathrm{Co}_{4} \mathrm{P}_{4} \mathrm{~W}_{30}, 8.77 \mathrm{mg} ; \mathrm{CoPW}_{11}, 3.20 \mathrm{mg} ; \mathrm{a}_{1-}$ $\mathrm{CoP}_{2} \mathrm{~W}_{17}, 4.86 \mathrm{mg} ; \mathrm{a}_{2}-\mathrm{CoP}_{2} \mathrm{~W}_{17}, 4.82 \mathrm{mg}$. Next, $1 \mathrm{~mL}$ of $200 \mathrm{mM}$ $\mathrm{NaPi}\left(\mathrm{pH} 5.8\right.$ or 8.0 ), $500 \mu \mathrm{L} \mathrm{D}_{2} \mathrm{O}$, and $500 \mu \mathrm{L}$ water were added to the Co-POM powder in the 1 dram vial, yielding $2 \mathrm{~mL}$ of a solution with $500 \mu \mathrm{M}$ Co-POM, $100 \mathrm{mM} \mathrm{NaPi}$, and $25 \% \mathrm{D}_{2} \mathrm{O}$. The timer was started immediately upon addition of the buffer solution to the solid Co-POM. A $1 \mathrm{~mL}$ aliquot was then transferred into a $5 \mathrm{~mm}$ OD NMR tube which was then inserted into the NMR. ${ }^{31} \mathrm{P}$ NMR was then collected on the sample without shimming and under conditions identical to those used for the calibration curve. A $500 \mathrm{MHz}$ Varian NMR spectrometer was used at $25^{\circ} \mathrm{C}$ with scans from +64.9 to -64.9 $\mathrm{ppm}$, a $45^{\circ}$ pulse angle, a $1.000 \mathrm{~s}$ relaxation delay, and a $0.624 \mathrm{~s}$ acquisition time. The peak width of the ${ }^{31} \mathrm{P}$ NMR peaks were determined using the instrument's VNMRJ software after phase correction.

To confirm the line broadening is caused almost completely by $\mathrm{Co}(\mathrm{II})_{\mathrm{aq}}$ and not by the Co(II) present within the intact Co-POM, we conducted the same experiments as above except in the presence of $92 \mu \mathrm{M}$ EDTA to complex any free Co(II) (i.e., an amount of EDTA in 1.2-10-fold excess of the $\mathrm{Co}(\mathrm{II})_{\mathrm{aq}}$ detected by the initial ${ }^{31} \mathrm{P}$ NMR experiment for $\mathrm{Co}_{4} \mathrm{P}_{4} \mathrm{~W}_{30}$ and $\mathrm{\alpha}_{1}-\mathrm{CoP}_{2} \mathrm{~W}_{17}$ for example). Any residual line broadening over that original ${ }^{31} \mathrm{P}$ NMR was then assigned to the intact Co-POM, an amount that ranged from just 2 to $8 \mathrm{~Hz}$, so only between 1.3 and $6 \mu \mathrm{M} \mathrm{Co}(\mathrm{II})_{\mathrm{aq}}$ for $\mathrm{Co}_{4} \mathrm{P}_{2} \mathrm{~W}_{18}$ and $\mathrm{Co}_{4} \mathrm{P}_{4} \mathrm{~W}_{30}$ in $0.1 \mathrm{M} \mathrm{NaPi} \mathrm{pH}=8.0$. This in turn means that the contribution from the intact Co-POMs to the observed ${ }^{31} \mathrm{P}$ NMR line broadening is at most only $8 \%$ of the $\mathrm{Co}(\mathrm{II})_{\mathrm{aq}}$ detected for $\mathrm{Co}_{4} \mathrm{P}_{4} \mathrm{~W}_{30}$ in $0.1 \mathrm{M} \mathrm{NaPi} \mathrm{pH}=8.0$. The residual line broadening from the added EDTA experiment was subtracted from the raw fwhm values for the particular Co-POM being examined before the fwhm values were fit to the calibration curve to calculate the final $\mathrm{Co}(\mathrm{II})_{\mathrm{aq}}$ concentration.

For the $\mathrm{Co}(\mathrm{II})_{\mathrm{aq}}$ values that were close to the detection limit of the initial calibration curve (e.g., $\alpha_{1}-\mathrm{CoP}_{2} \mathrm{~W}_{17}$ at $\mathrm{pH}=5.8$ where the detected $\mathrm{Co}(\mathrm{II})_{\mathrm{aq}}$ was $\left.2.9 \pm 3 \mu \mathrm{M}\right)$ an additional calibration curve was generated that was able to more precisely determine the $\mathrm{Co}(\mathrm{II})_{\mathrm{aq}}$ and with a lower $<0.5 \mu \mathrm{M}$ detection limit (Figure S9 of the Supporting Information).

Stability of the Co-POMs As Determined by Cathodic Adsorptive Stripping As a Second Technique. The reliability of the ${ }^{31} \mathrm{P}$ NMR technique for the quantitation of $\mathrm{Co}(\mathrm{III})_{\mathrm{aq}}$ has been demonstrated for both $\mathrm{Co}_{4} \mathrm{P}_{2} \mathrm{~W}_{18}$ and $\mathrm{Co}_{4} \mathrm{~V}_{2} \mathrm{~W}_{18} \cdot{ }^{23,27}$ However, we wanted to determine the amount of $\mathrm{Co}(\mathrm{II})_{\mathrm{aq}}$ present in the $500 \mu \mathrm{M}$ Co-POM solutions in $\mathrm{pH} 9.0 \mathrm{NaB}$ after $3 \mathrm{~h}$ of aging (i.e., and under conditions where no $P_{i}$ is available for the use of the ${ }^{3} \mathrm{P}$ NMR method). Therefore, and as before ${ }^{23,27}$ an adsorptive cathodic stripping method was employed that quantifies $\mathrm{Co}(\mathrm{II})_{\mathrm{aq}}$ by adsorption of the neutral cobalt dimethylglyoxime (DMG) complex on a bismuth electrode and subsequent reductive stripping. $23,27,49$

Electrode Preparation. The Bi film electrode was prepared using a method adapted from previous studies..$^{23,27,49}$ First, a clean glassy carbon electrode (3 $\mathrm{mm}$ diameter), a $\mathrm{Ag} / \mathrm{AgCl}$ reference electrode, and a $\mathrm{Pt}$ wire counter electrode were placed into an aqueous solution containing $0.02 \mathrm{M} \mathrm{Bi}\left(\mathrm{NO}_{3}\right)_{3}, 0.5 \mathrm{M} \mathrm{LiBr}$, and $1 \mathrm{M} \mathrm{HCl}$. Then constant potential electrolysis was conducted at $-0.25 \mathrm{~V}$ until $10 \mathrm{mC}$ of charge had accumulated ( $45 \mathrm{~s})$. The electrodes were then removed and rinsed gently with water prior to being placed into the analyte solution containing either $\mathrm{Co}\left(\mathrm{NO}_{3}\right)_{2}$ for the calibration curve or the aged Co-POM solutions.

Calibration Curve. A calibration curve was developed using $\mathrm{Co}\left(\mathrm{NO}_{3}\right)_{2}$ as an authentic source of $\mathrm{Co}(\mathrm{II})_{\mathrm{aq}}$, with concentrations 
ranging from 1.0 to $50 \mu \mathrm{M} \mathrm{Co}(\mathrm{II})_{\mathrm{aq}}$ in $\mathrm{NaPi} \mathrm{pH} 8.0$ and $\mathrm{NaB} \mathrm{pH} 9.0$ (Figure S10 in the Supporting Information). Using freshly plated Bi films, the electrodes were placed into a 1 dram vial containing a buffered solution (either $0.1 \mathrm{M} \mathrm{NaPi} \mathrm{pH} 8.0$ or $0.1 \mathrm{M} \mathrm{NaB} \mathrm{pH} \mathrm{9.0)}$ that contained the desired $\mathrm{Co}\left(\mathrm{NO}_{3}\right)_{2}$ concentration and $100 \mu \mathrm{M}$ DMG. The solution was stirred for $3 \mathrm{~s}$ and allowed to reach stillness, and then the $\mathrm{CoDMG}_{2}$ was adsorbed by applying $-1.3 \mathrm{~V}$ to the $\mathrm{Bi}$ film electrode for $15 \mathrm{~s}$. The solution was again stirred for $3 \mathrm{~s}$ and allowed to settle before differential pulse voltammetry (DPV) from -0.7 to $-1.3 \mathrm{~V}$ using a $0.1 \mathrm{~s}$ pulse width, $50 \mathrm{mV}$ amplitude, and a $0.0167 \mathrm{~s}$ sampling width. The height of the DPV waves were measured from the background using the $\mathrm{CH}$ Instruments software, and plotted against the known $\mathrm{Co}(\mathrm{II})_{\mathrm{aq}}$ concentration for the calibration curves (Figure S10 in the Supporting Information). Worth noting is that the use of $\mathrm{pH}=8.0$ to 9.0 buffer is essential because at $\mathrm{pH}=5.8$ the adsorptive cathodic stripping is not responsive to the $\mathrm{Co}(\mathrm{II})_{\mathrm{aq}}$ concentration, likely because the DMG must be deprotonated by $\mathrm{pH}>5.8$ to form $\mathrm{Co}(\mathrm{DMG})_{2}$ that is an intermediate in the Co-stripping on the Bi film.

Aging of the Co-POMs and Cathodic Stripping. First, $500 \mu \mathrm{M}$ solutions of the Co-POMs were prepared by weighing an appropriate amount of the solid Co-POM material into a 1 dram vial and then adding $2 \mathrm{~mL}$ of either $0.1 \mathrm{M} \mathrm{NaPi} \mathrm{pH} 8.0$ or $\mathrm{NaB} \mathrm{pH} 9.0$. The solutions were then aged $3 \mathrm{~h}$ before an aliquot, typically $200 \mu \mathrm{L}$, was used in the same analyte solution as the calibration curve. (While as noted the aliquot was typically $200 \mu \mathrm{L}$, the actual microliter volume of the aliquot was adjusted such that the detected $\mathrm{Co}(\mathrm{II})_{\mathrm{aq}}$ concentration was within the calibration curve's linear range of $1-$ $10 \mu \mathrm{M}$, as explained in greater detail below.) Because DMG binding of $\mathrm{Co}(\mathrm{II})$ could, in principle, shift the Co-POM dissociative equilibrium yielding a larger $\mathrm{Co}(\mathrm{II})_{\mathrm{aq}}$ concentration than without DMG, the time between aliquot addition and cathodic stripping was kept to a minimum $(<1 \mathrm{~min})$. The $\operatorname{Co}(\mathrm{DMG})_{2}$ deposition and the DPV were conducted in the same manner as for the calibration curve above. The peak height of the DPV was fit to the calibration curves (Figure S10 of the Supporting Information), and the results were used to calculate the $\mathrm{Co}(\mathrm{II})_{\mathrm{aq}}$ concentration in the analyte solutions. The $\mathrm{Co}(\mathrm{II})_{\mathrm{aq}}$ concentration in the original solution was determined by taking into account the 1:10 dilution from the original solution to the analyte solution. For cases where the measured $\mathrm{Co}(\mathrm{II})_{\mathrm{aq}}$ was not within the linear range of the calibration curve, the dilution factor from the original to the analyte solution was adjusted so that the detected $\mathrm{Co}(\mathrm{II})_{\mathrm{aq}}$ concentration was within the range of the linear calibration curve. For example, the $\mathrm{Co}(\mathrm{II})_{\mathrm{aq}}$ detected from a 1:10 dilution of $\mathrm{CoPW}_{11}$ is $\gg 10 \mu \mathrm{M}$ and therefore outside the linear range of the calibration curve. Instead, a $20 \mu \mathrm{L}$ aliquot of the aged $\mathrm{CoPW}_{11}$ was used (a 1:100 dilution) and the $\mathrm{Co}(\mathrm{II})_{\mathrm{aq}}$ concentration in the diluted solution was determined to be $4.4 \pm 0.5 \mu \mathrm{M}$, meaning that the actual $\mathrm{Co}(\mathrm{II})_{\mathrm{aq}}$ concentration in the original, undiluted $\mathrm{CoPW}_{11}$ solution was 100 -fold larger, specifically $440 \pm 50 \mu \mathrm{M}$.

Electrocatalytically Driven Water Oxidation Catalysis Beginning with the Co-POMs. Electrolysis Using the Co-POMs in Buffered Solutions in Comparison with $\mathrm{Co}(\mathrm{II})_{\mathrm{aq}}$. From the ${ }^{31} \mathrm{P}$ NMR and cathodic stripping studies, the amount of $\mathrm{Co}(\mathrm{II})_{\mathrm{aq}}$ that dissociates into buffered solution after $3 \mathrm{~h}$ is known. Comparing the observed activity of the aged Co-POM solutions with solutions containing authentic $\mathrm{Co}(\mathrm{II})_{\mathrm{aq}}$ tests if the WOCatalysis activity can be accounted for by the dissociated $\mathrm{Co}(\mathrm{II})_{\mathrm{aq}}$ or, alternatively, if WOCatalysis by the Co-POM itself is indicated. Hence, we conducted bulk electrolysis using a $1 \mathrm{~cm}^{2}$ working electrode in buffered solutions that either contained a $500 \mu \mathrm{M}$ Co-POM solution that had aged $3 \mathrm{~h}$ or an amount of authentic $\mathrm{Co}(\mathrm{II})_{\mathrm{aq}}$ that matched the measured $\mathrm{Co}(\mathrm{II})_{\mathrm{aq}}$ after $3 \mathrm{~h}$, as determined by ${ }^{31} \mathrm{P}$ NMR or cathodic stripping.

Electrolysis was conducted in the same manner as previous studies using $\mathrm{Co}_{4} \mathrm{~V}_{2} \mathrm{~W}_{18}$ as a WOPrecatalyst. ${ }^{27}$ Briefly, the experiments were conducted in a custom built U-cell with a medium fritted glass filter separating the working and counter electrodes. The working compartment was sealed using a Teflon lid pierced to accommodate the working electrode, the reference electrode, and the $\mathrm{O}_{2}$ detection sensor (NeoFox; FOSPOR-R probe), all in a $6 \mathrm{~mL}$, argon-purged solution. The headspace was kept to a minimum in order to diminish $\mathrm{O}_{2}$ equilibration with the headspace which otherwise results in an excessively systematically low measured $\mathrm{O}_{2}$ concentration and low apparent faradaic efficiency. The $\mathrm{O}_{2}$ sensor was calibrated using a 2point calibration curve consisting of air-saturated DI water $(\sim 220 \mu \mathrm{M}$ at $22{ }^{\circ} \mathrm{C}$, for a typical barometric pressure of 0.84 atm for Fort Collins, $\mathrm{CO}$ ), and $\mathrm{O}_{2}$-free solutions were generated by addition of excess sodium sulfite to the solution. Electrolysis was conducted at 1.1 $\mathrm{V}$ for $5 \mathrm{~min}$ with stirring at $\sim 600 \mathrm{rpm}$. The final faradaic efficiency was determined by comparing the final $\mathrm{O}_{2}$ concentration to the $\mathrm{O}_{2}$ concentration expected from the total charge passed during the experiment (i.e., $4 \mathrm{e}^{-}$passed per $1 \mathrm{O}_{2}$ produced).

Electrochemical and Morphological Characterization of the Films Electrodeposited from the Co-POM Solutions. Deposition and Cyclic Voltammograms of $\mathrm{CoO}_{x}$ Films. Previous work has documented the value of controlled potential electrolysis and subsequent analysis of deposited films from Co-POMs. ${ }^{23,27}$ As such, controls were conducted in a similar manner in which constant potential electrolysis was conducted at $1.1 \mathrm{~V}$ on a glassy carbon electrode for 5-30 min to allow sufficient accumulation of an electrodeposited film to be visible to the naked eye. After electrolysis, cyclic voltammetry was conducted on the film in the same Co-POM solution. The electrodes were subsequently removed from the original Co-POM solution, rinsed with water, and placed into a buffer-only solution. Cyclic voltammetry was then conducted on the electrodeposited film in the buffer-only solution-this allows comparison of the observed WOCatalysis activity from the deposited film to that of the starting Co-POM solution. Electrolysis was then conducted on the deposited film in the buffer-only solution under otherwise identical conditions to the Co-POM solution.

To test the hypothesis that $\mathrm{CoO}_{\mathrm{x}}$ forms from $\mathrm{Co}(\mathrm{II})_{\mathrm{aq}}$, and not directly from Co-POM bound to the electrode surface, EDTA was added at a concentration 10 times the measured $\mathrm{Co}(\mathrm{II})_{\mathrm{aq}}$. Constant potential electrolysis at $1.1 \mathrm{~V}$ was then conducted. Controls with $\mathrm{Co}\left(\mathrm{NO}_{3}\right)_{2}$ and EDTA present demonstrate that no film is deposited from the Co.EDTA complex. This, in turn, means that if a film is observed from any Co-POM solution containing 10 equiv of EDTA/ $\mathrm{Co}(\mathrm{II})_{\mathrm{aq}}$, then that film would have to be formed from some route not involving freely diffusing $\mathrm{Co}(\mathrm{II})_{\mathrm{aq}}$, for example, conceivably directly from Co-POM adsorbed on the electrode.

Morphological and Compositional Analysis of the Deposited Films. The electrodeposited films were examined by XPS and SEM to quantify elements in the surface of the film, and to capture morphological features, respectively. The films were deposited on glassy carbon $\left(1 \mathrm{~cm}^{2}\right)$ at $1.1 \mathrm{~V}$ for $30 \mathrm{~min}$ from Co-POM solutions in $0.1 \mathrm{M} \mathrm{NaPi}$ pH 5.8 and 8.0 as well as $0.1 \mathrm{M} \mathrm{NaB} \mathrm{pH} \mathrm{9.0.} \mathrm{The}$ electrodes were then removed from solution and allowed to air-dry on the bench before being placed into a desiccator overnight. XPS was conducted on a PE-5800 X-ray photoelectron spectrometer; survey scans were collected from 10 to $1100 \mathrm{eV}$ with $1.6 \mathrm{eV} / \mathrm{step}$ and 187.85 $\mathrm{eV}$ pass energy. High resolution scans were collected for each element detected from the survey (such that sufficient background was included with $0.1 \mathrm{eV} / \mathrm{step}$ and $23.5 \mathrm{eV}$ pass energy). SEM was conducted on a JEOL JSM 6500F scanning electron microscope. Images were collected from $1000 \times$ to $20000 \times$ magnification to demonstrate the homogeneity of the film as well as to visualize morphological details.

\section{RESULTS AND DISCUSSION}

Stability of the Co-POMs Assayed by Co(II) $)_{\mathrm{aq}}$-Induced ${ }^{31} \mathrm{P}$ NMR Line Broadening. Quantitative knowledge of the stability of any precatalyst under a given set of conditions is crucial to understanding the kinetically dominant, most active form of the catalyst. ${ }^{23,25-27}$ Using the $\mathrm{Co}(\mathrm{II})_{\mathrm{aq}}$-induced, ${ }^{31} \mathrm{P}$ NMR line-broadening experiments first developed by Klanberg and Dodgen ${ }^{46}$ and then Nocera and co-workers, ${ }^{28,47}$ the amount of $\mathrm{Co}(\mathrm{II})_{\mathrm{aq}}$ present as a function of time for each $\mathrm{Co}-$ POM was measured in NaPi pH 5.8 and 8.0. The $\mathrm{Co}(\mathrm{II})_{\mathrm{aq}}$ vs time traces for selected Co-POMs are shown in Figure 2 and 

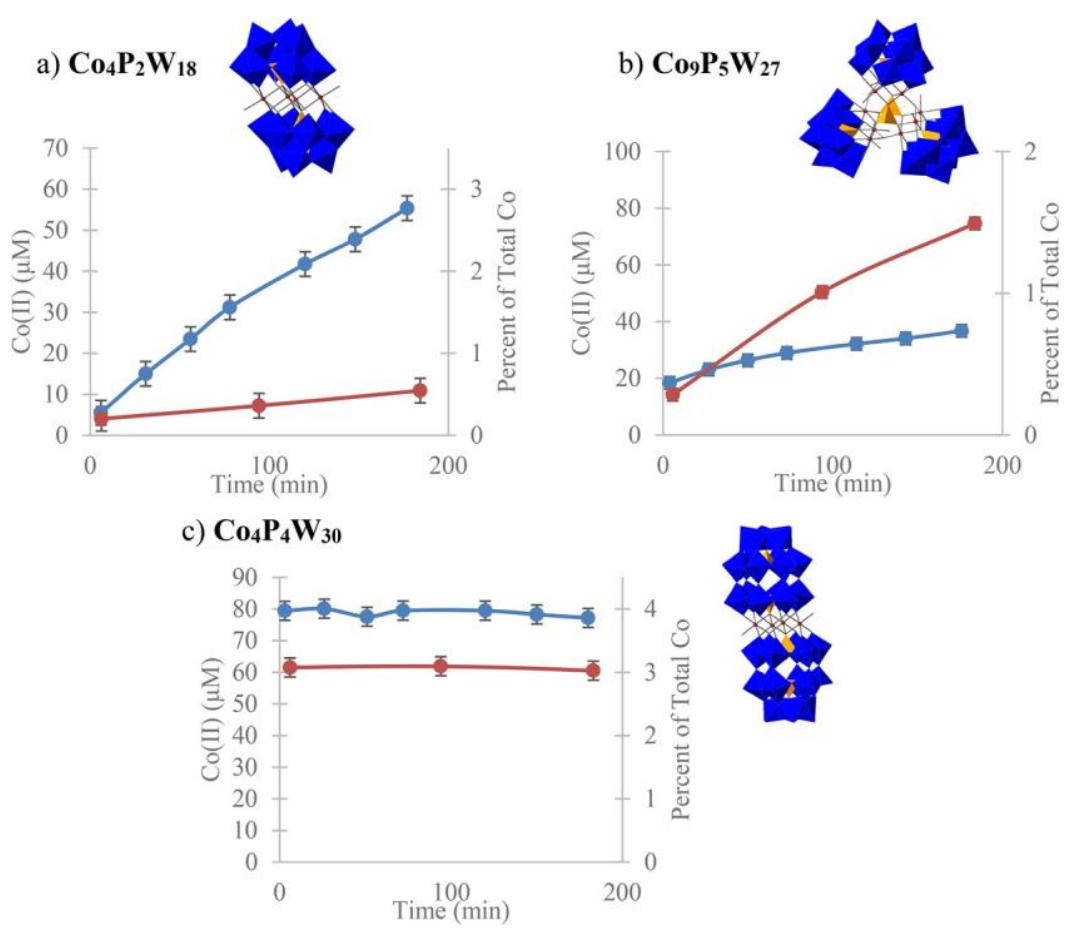

Figure 2. $\mathrm{Co}(\mathrm{II})_{\mathrm{aq}}$ concentration vs time determined by $\mathrm{Co}(\mathrm{II})_{\mathrm{aq}}$ induced line broadening in $0.1 \mathrm{M} \mathrm{NaPi}(\mathrm{pH} 5.8$, red and $\mathrm{pH} 8.0$, blue) for 500 $\mu \mathrm{M}$ solutions of (a) $\mathrm{Co}_{4} \mathrm{P}_{2} \mathrm{~W}_{18}$ (adapted with permission from ref 27, Copyright 2017 American Chemical Society); (b) Co $\mathrm{Co}_{5} \mathrm{~W}_{27}$; and (c) $\mathrm{Co}_{4} \mathrm{P}_{4} \mathrm{~W}_{30}$. The value for each $\mathrm{Co}(\mathrm{II})_{\mathrm{aq}}$ concentration was determined by fitting the observed ${ }^{31} \mathrm{P}$ NMR line widths of the NaPi to the calibration curve generated with authentic $\mathrm{Co}\left(\mathrm{NO}_{3}\right)_{2}$. The percent of total cobalt refers to the percent of cobalt that is detected in solution compared to the total Co(II) present initially in the specific Co-POM. Error bars are the standard deviation from three repeat experiments. The lines between points have been added to guide the eye and, hence, are not fits to any specific equation. The Co(II) $)_{\mathrm{aq}}$ vs time plots for the other Co-POMs are shown in Figure S11 of the Supporting Information.

Figure S11 of the Supporting Information. The percent of total $\mathrm{Co}$ (II) in the Co-POM solution that is present as aqueous $\mathrm{Co}(\mathrm{II})_{\mathrm{aq}}$ after $3 \mathrm{~h}$ of aging is presented in Figure 3 and Table 1. All of the Co-POMs examined showed some detectable $\mathrm{Co}(\mathrm{II})_{\mathrm{aq}}$ over $3 \mathrm{~h}$ in NaPi buffer ranging from $\sim 0.25$ to $50 \%$ (in NaPi buffer) of the total $\mathrm{Co}$ (II) present in the given Co-POM solution, the exact percentage depending on the Co-POM and the precise $\mathrm{pH}$ and buffering conditions, vide infra.

Three of the Co-POMs examined, specifically $\mathrm{Co}_{4} \mathrm{P}_{2} \mathrm{~W}_{18}$, $\mathrm{Co}_{9} \mathrm{P}_{5} \mathrm{~W}_{27}$, and $\mathrm{CoPW}_{11}$, show increasing concentration of $\mathrm{Co}$ (II) leached into solution over $3 \mathrm{~h}$ at $\mathrm{pH}=8.0$ and 5.8, Figure 2 and Figure S11 of the Supporting Information. For these cases, the detected, increasing $\mathrm{Co}(\mathrm{II})_{\mathrm{aq}}$ is most simply attributed to (continued) dissociation of $\mathrm{Co}$ (II) from the Co$\mathrm{POM}$ precatalyst. One interesting point to note is that while $\mathrm{Co}_{4} \mathrm{P}_{2} \mathrm{~W}_{18}$ is more stable at $\mathrm{pH}=5.8, \mathrm{Co}_{9} \mathrm{P}_{5} \mathrm{~W}_{27}$ is more stable at $\mathrm{pH}=8.0$. This is consistent with the fact that a mixture of $\mathrm{Co}_{4} \mathrm{P}_{2} \mathrm{~W}_{18}$ and $\mathrm{Co}_{9} \mathrm{P}_{5} \mathrm{~W}_{27}$ is obtained from reactions of $\mathrm{HPO}_{4}{ }^{2-}, \mathrm{Co}(\mathrm{II})$, and $\mathrm{WO}_{4}{ }^{2-},{ }^{30}$ with $\mathrm{Co}_{9} \mathrm{P}_{5} \mathrm{~W}_{27}$ being more prevalent at the more basic $\mathrm{pH}>7 .{ }^{31}$ Restated, this evidence suggests unsurprisingly that individual Co-POMs tend to be more stable in the $\mathrm{pH}$ range where they are synthesized. Leaching of $\mathrm{Co}(\mathrm{II})_{\mathrm{aq}}$ from the complex is consistent with hypothesis \#3 from Scheme 1 for the above three Co-POMs.

The other three Co-POMs, $\mathrm{Co}_{4} \mathrm{P}_{4} \mathrm{~W}_{30}, \mathrm{a}_{1}-\mathrm{CoP}_{2} \mathrm{~W}_{17}$, and $\mathrm{a}_{2}-\mathrm{CoP}_{2} \mathrm{~W}_{17}$, show detectable, 0.25( \pm 0.06$)-3.9( \pm 0.1) \%$ but relatively flat $\mathrm{Co}(\mathrm{II})_{\mathrm{aq}}$ over $3 \mathrm{~h}$ at $\mathrm{pH} 5.8$ and 8.0 (with the exception of $\mathrm{\alpha}_{2}-\mathrm{CoP}_{2} \mathrm{~W}_{17}$ at $\mathrm{pH} 8.0$, vide infra). Note that all of the Co-POMs have non-zero amounts of $\mathrm{Co}(\mathrm{III})_{\mathrm{aq}}$ detected that are well above the detection limit $(\sim 2 \mu \mathrm{M}$ generally, but $\sim 0.5 \mu \mathrm{M}$ for $\mathrm{\alpha}_{1}-\mathrm{CoP}_{2} \mathrm{~W}_{17}$ at $\mathrm{pH}=5.8$ using our third, more precise, lowest $\left[\mathrm{Co}(\mathrm{II})_{\mathrm{aq}}\right]$ calibration curve described in the Experimental section and Figure S9 of the Supporting Information, which focuses on the lower concentrations of $0.5,1,5$, and $\left.20 \mu \mathrm{M} \mathrm{Co}(\mathrm{II})_{\mathrm{aq}}\right)$. Three repetitions of each of these lower $\left[\mathrm{Co}(\mathrm{II})_{\mathrm{aq}}\right]$ were conducted using $\alpha_{1}-\mathrm{CoP}_{2} \mathrm{~W}_{17}$ at $\mathrm{pH}=5.8$, with the key result that the detected amount of $\mathrm{Co}(\mathrm{II})_{\mathrm{aq}}$ for $\mathrm{\alpha}_{1}-\mathrm{CoP}_{2} \mathrm{~W}_{17}$ at $\mathrm{pH}=5.8$ is $1.2 \pm 0.3 \mu \mathrm{M}$. In short, the detected $\mathrm{Co}(\mathrm{II})_{\mathrm{aq}}$ for $\mathrm{a}_{1}-\mathrm{CoP}_{2} \mathrm{~W}_{17}$ at $\mathrm{pH}=5.8$ is also experimentally non-zero, as well as relatively flat.

A flat $\mathrm{Co}(\mathrm{II})_{\mathrm{aq}}$ vs time dependence implies either: (i) that rapid $\mathrm{Co}(\mathrm{II})_{\mathrm{aq}}$ dissociation from the $\mathrm{Co}-\mathrm{POM}$ to reach equilibrium quickly has occurred, or (ii) that the $\mathrm{Co}(\mathrm{III})_{\mathrm{aq}}$ is present as a countercation to the Co-POM from the synthesis (or, conceivably (iii) a combination of (i) and (ii)). If the $\mathrm{Co}(\mathrm{II})_{\mathrm{aq}}$ is, in fact, present as a countercation, then one might expect to observe a high $\mathrm{Co}$ (II) weight percent (wt \%) in the elemental analysis.

As a specific example, the weight percent of Co by elemental analysis for $\mathrm{Na}_{16}\left[\beta \beta-\mathrm{Co}_{4}\left(\mathrm{H}_{2} \mathrm{O}\right)_{2}\left(\mathrm{P}_{2} \mathrm{~W}_{15} \mathrm{O}_{56}\right)_{2}\right] \cdot 39 \mathrm{H}_{2} \mathrm{O}$ $\left(\mathrm{Co}_{4} \mathrm{P}_{4} \mathrm{~W}_{30}\right)$ is the same within experimental error, with a found Co wt $\%$ of $2.62 \%$ vs the expected $2.69 \%$. Furthermore, the molar amount of $\mathrm{Co}(\mathrm{II})$ present in the $\mathrm{Co}_{4} \mathrm{P}_{4} \mathrm{~W}_{30}$ solutions (14-16\% mol of $\mathrm{Co}(\mathrm{II}) / \mathrm{mol} \mathrm{Co}-\mathrm{POM})$ is not distinguishable if one assumes an error of \pm 0.4 absolute wt $\%$. Indeed, the expected wt $\%$ cobalt would change from $2.69 \%$ for the elemental formula of the pure $\mathrm{Na}_{16} \beta \beta$ $\left[\mathrm{Co}_{4}\left(\mathrm{H}_{2} \mathrm{O}\right)_{2}\left(\mathrm{P}_{2} \mathrm{~W}_{15} \mathrm{O}_{56}\right)\right] \cdot 39 \mathrm{H}_{2} \mathrm{O}$ to $2.81 \%$ for the hypothetical case where $16 \mathrm{~mol} \%$ of $\mathrm{Co}(\mathrm{II}) / \mathrm{Co}_{4} \mathrm{P}_{4} \mathrm{~W}_{30}$ as a countercation was present for a (hypothetical) elemental formula of $\mathrm{Na}_{15.68} \mathrm{Co}_{0.16}\left[\beta \beta-\mathrm{Co}_{4}\left(\mathrm{H}_{2} \mathrm{O}\right)_{2}\left(\mathrm{P}_{2} \mathrm{~W}_{15} \mathrm{O}_{56}\right)_{2}\right] \cdot 39 \mathrm{H}_{2} \mathrm{O}$, a difference of only $0.11 \mathrm{wt} \%$. In short, a publishable $( \pm 0.4 \%$ 


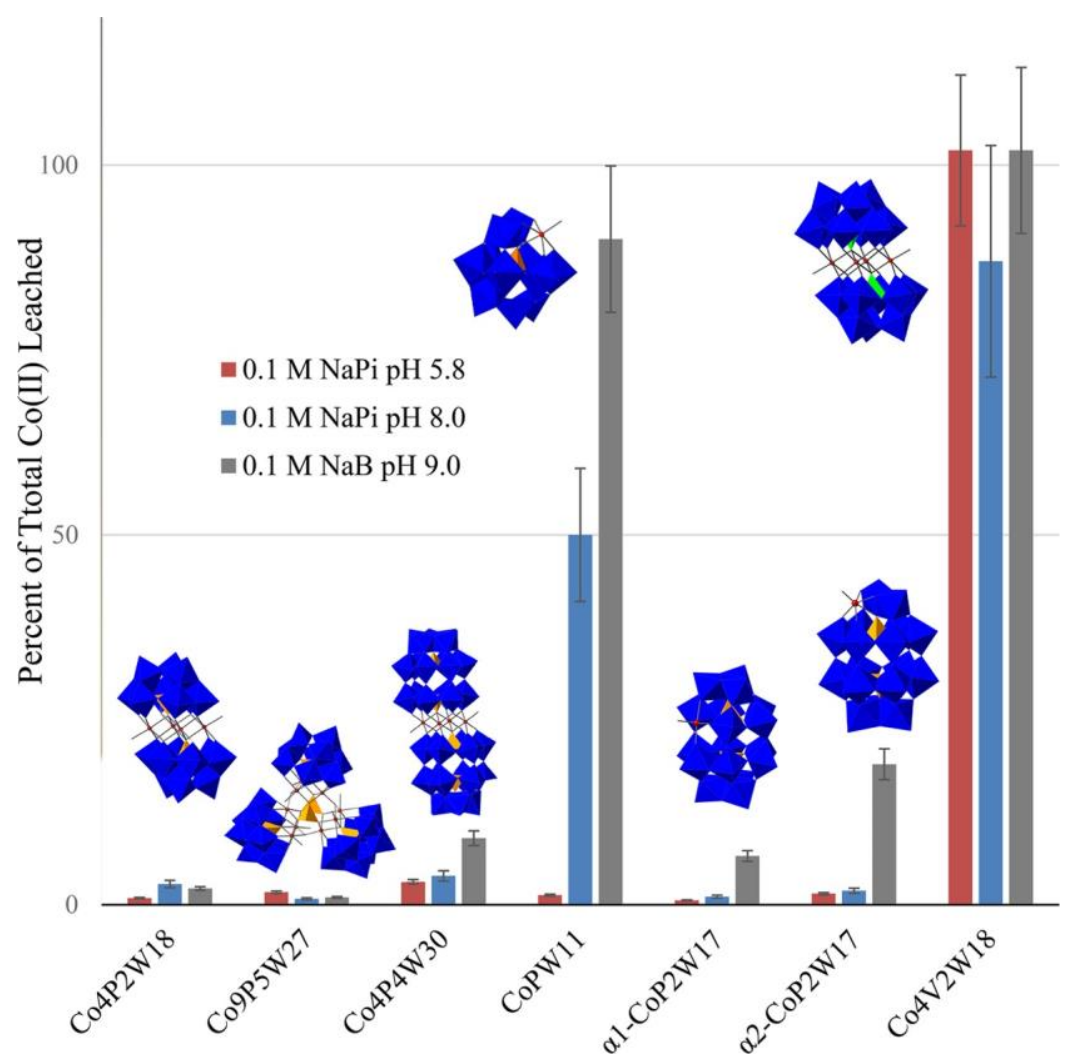

Figure 3. Percent of total cobalt that is present as $\mathrm{Co}(\mathrm{II})_{\mathrm{aq}}$ after $3 \mathrm{~h}$ of aging in solution for $500 \mu \mathrm{M}$ solutions of each Co-POM in $0.1 \mathrm{M} \mathrm{NaPi}$, $\mathrm{pH}$ $=5.8$ (red) and $\mathrm{pH}=8.0$ (blue), as well as in $0.1 \mathrm{M} \mathrm{NaB} \mathrm{pH}=9.0$ (gray). Decomposition data for $\mathrm{Co}_{4} \mathrm{~V}_{2} \mathrm{~W}_{18}$ has been adapted with permission from ref 26 (Copyright 2017 American Chemical Society) for comparison with the other Co-POMs, albeit with a $5 \mu \mathrm{M} \mathrm{Co-POM} \mathrm{concentration}$ under otherwise identical conditions. The lower concentration of $\mathrm{Co}_{4} \mathrm{~V}_{2} \mathrm{~W}_{18}$ had to be used because $\mathrm{Co}_{4} \mathrm{~V}_{2} \mathrm{~W}_{18}$ is so unstable that, at $500 \mu \mathrm{M}$, the $\mathrm{Co}(\mathrm{II})_{\mathrm{aq}}$ detected is otherwise above the linear range of the calibration curve.

absolute wt \%) elemental analysis is not sufficient evidence to disprove $\mathrm{Co}(\mathrm{II})$ impurities as counter cations present in $\mathrm{Co}_{4} \mathrm{P}_{4} \mathrm{~W}_{30}$ nor, by analogy, more generally in other Co-POMs.

To provide evidence for or against $\mathrm{Co}(\mathrm{II})_{\mathrm{aq}}$ being present as a countercation vs the rapid dissociation of $\mathrm{Co}$ (II) from $\mathrm{Co}_{4} \mathrm{P}_{4} \mathrm{~W}_{30}$ to an equilibrium value, we conducted ${ }^{31} \mathrm{P} \mathrm{NMR}$ control experiments by adding 1 equiv of EDTA/Co(II) $)_{\mathrm{aq}}$ to the $\mathrm{Co}_{4} \mathrm{P}_{4} \mathrm{~W}_{30}$ solutions and, then, repeated the ${ }^{31} \mathrm{P}$ NMR linebroadening experiment, Figure 4. The results of that experiment show that addition of 1 equiv of EDTA/Co(II) $)_{\mathrm{aq}}$ lowers-but does not remove all-of the detected $\mathrm{Co}(\mathrm{II})_{\mathrm{aq}}$ (black dashed line, Figure 4). Furthermore, an important observation is that the $\mathrm{Co}(\mathrm{II})_{\mathrm{aq}}$ concentration does not immediately return to the higher, $60-80 \mu \mathrm{M}$ value, thereby ostensibly ruling out a fast, initial release of $\mathrm{Co}(\mathrm{II})_{\mathrm{aq}}$ to reach an equilibrium level at either $\mathrm{pH}$ of 8.0 or 5.8. Addition of an excess, $100 \mu \mathrm{M}$ amount of EDTA does remove all of the observed $\mathrm{Co}(\mathrm{II})_{\mathrm{aq}}$, which then remains at zero and hence constant within experimental error over the $3 \mathrm{~h}$ experiment (black solid line, Figure 4). In short, the data suggest that the $\mathrm{Co}(\mathrm{II})_{\mathrm{aq}}$ being detected is present initially at a countercation attached tightly to the highly negatively charged, $[\beta \beta-$ $\left.\mathrm{Co}_{4}\left(\mathrm{H}_{2} \mathrm{O}\right)_{2}\left(\mathrm{P}_{2} \mathrm{~W}_{15} \mathrm{O}_{56}\right)_{2}\right]^{16-}$ polyoxopolyanion and, therefore, not available to contribute to the phosphate line broadening to any great extent. Such tight-ion pairing between a dicationic $\mathrm{Co}(\mathrm{II})^{2+}$ and the 16 minus POM, $[\beta \beta-$ $\left.\mathrm{Co}_{4}\left(\mathrm{H}_{2} \mathrm{O}\right)_{2}\left(\mathrm{P}_{2} \mathrm{~W}_{15} \mathrm{O}_{56}\right)_{2}\right]^{16-}$, even in water is not unreasonable nor unexpected.
The evidence provided above demonstrates that there is an EDTA-removable amount of additional ${ }^{31} \mathrm{P}$ NMR line broadening in the $\mathrm{Co}_{4} \mathrm{P}_{4} \mathrm{~W}_{30}$ system, consistent with an additional amount of tight ion paired $\mathrm{Co}$ (II) attached to the $\left[\beta \beta-\mathrm{Co}_{4}\left(\mathrm{H}_{2} \mathrm{O}\right)_{2}\left(\mathrm{P}_{2} \mathrm{~W}_{15} \mathrm{O}_{56}\right)_{2}\right]^{16-}$. It is therefore reasonable to sum the observed $\mathrm{Co}(\mathrm{II})_{\mathrm{aq}}$ in the absence of EDTA with the observed $\mathrm{Co}(\mathrm{II})_{\mathrm{aq}}$ seen upon the addition of 1 equiv of EDTA to give the total apparent $\mathrm{Co}(\mathrm{II}) \mathrm{aq}$ as shown in Figure 4. Specifically, one can calculate that in $\mathrm{pH}=5.8$ buffer, the total $\mathrm{Co}(\mathrm{II})_{\mathrm{aq}}$ value $=62( \pm 1)+19( \pm 2)=81( \pm 2) \mu \mathrm{M}$ (i.e., the solid red line plus the dashed black line yields the dashed red line in Figure 4), while in $\mathrm{pH}=8.0$ the total $\mathrm{Co}(\mathrm{II})_{\mathrm{aq}}=78( \pm 2)$ $+10( \pm 3)=88( \pm 4)$ (i.e., the solid blue line plus the dashed black line yields the dashed blue line in Figure 4). Averaging the $\mathrm{pH} 5.8$ and 8.0 data yields a $\mathrm{Co}(\mathrm{II})_{\mathrm{aq}}$ value of $85( \pm 4) \mu \mathrm{M}$ as an estimate of the amount of $\mathrm{Co}(\mathrm{III})_{\mathrm{aq}}$ present as a countercation from the synthesis in $\mathrm{Co}_{4} \mathrm{P}_{4} \mathrm{~W}_{30}$. The systematic difference of the measured $\mathrm{Co}(\mathrm{III})_{\mathrm{aq}}$ in $\mathrm{pH} 5.8$ vs 8.0 of $62( \pm 1)$ vs $78( \pm 2) \mu \mathrm{M}$, respectively, is discussed in the Supporting Information for the interested reader.

The observation of $\mathrm{Co}$ (II) as a countercation is an important finding for at least two reasons, the first of which is because it provides evidence for hypothesis \#2 from Scheme 1 , where $\mathrm{Co}$ (II) is present as a normally undetected impurity in the postsynthesis $\mathrm{Co}_{4} \mathrm{P}_{4} \mathrm{~W}_{30} \cdot{ }^{28}$ Second, the results in Figure 4 are significant as they imply that the presence of dication impurities in the syntheses of highly charged POMs is very likely a little recognized, but more general, phenomenon in polyoxometalate and other polyanionic self-assembly syntheses. 

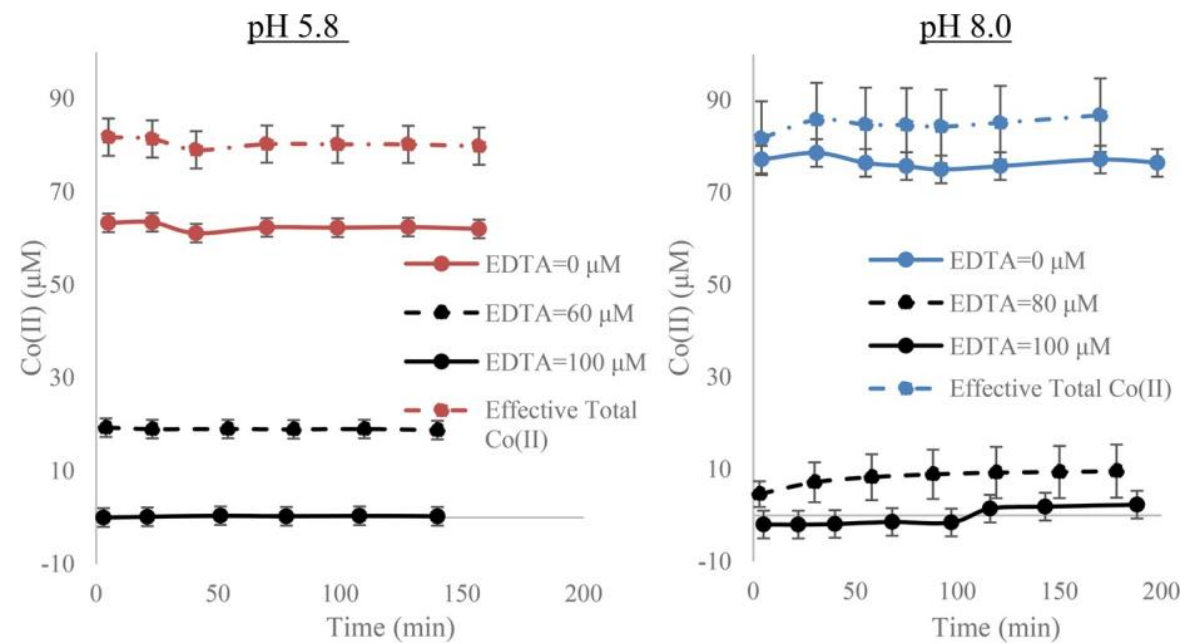

Figure 4. Plots of $\mathrm{Co}(\mathrm{II})_{\mathrm{aq}}$ concentration vs time for a $500 \mu \mathrm{M}$ solution of $\mathrm{Co}_{4} \mathrm{P}_{4} \mathrm{~W}_{30}$ in $0.1 \mathrm{M} \mathrm{NaPi}(\mathrm{pH} 5.8$, left and $\mathrm{pH} 8.0$, right). The red and blue lines are for $\mathrm{Co}_{4} \mathrm{P}_{4} \mathrm{~W}_{30}$ in the absence of any added EDTA (i.e., the same as Figure 2), the dashed black lines are for experiments where 1 equiv of EDTA/Co(II) $)_{\text {aq }}$ has been added $(60$ and $80 \mu \mathrm{M}$ for pH 5.8 and 8.0 ,respectively), and solid black lines represent the addition of excess EDTA $(100 \mu \mathrm{M})$. The dashed red and blue lines represent the true Co(II) $)_{\mathrm{aq}}$ concentration (i.e., the sum of the solid colored line with the dashed black line for each $\mathrm{pH}$ condition.

Because of the intrinsically high molecular weight of large POM anions, low levels of countercation impurities are difficult to detect via standard elemental analysis methods such as ICP-OES (vide supra). This highlights the power of the $\mathrm{Co}(\mathrm{II})_{\mathrm{aq}}$-induced ${ }^{31} \mathrm{P}$ NMR line-broadening technique because it has high selectivity toward $\mathrm{Co}(\mathrm{II})_{\text {aq }}$ with a detection limit of $\sim 2 \mu \mathrm{M} \mathrm{Co}$ (II $)_{\mathrm{aq}}$, which in turn corresponds to $\sim 0.4$ mol \% regardless of the molar mass of the Co-POM. Future research using Co-POMs for WOCatalysis should use ${ }^{31} \mathrm{P}$ NMR line broadening to quantify $\mathrm{Co}(\mathrm{II})_{\mathrm{aq}}$ because it is likely present in at least some as-synthesized Co-POMs. However, the $\mathrm{Co}(\mathrm{II})_{\mathrm{aq}}$-induced ${ }^{31} \mathrm{P} \mathrm{NMR}$ methods herein can now be used on Co-POMs that are, for example, not run down ionexchange columns or not exposed to multiple recrystallizations from, say, $\mathrm{Na}^{+}, \mathrm{K}^{+}$, or other desired cation-containing recrystallization solutions.

${ }^{31} \mathrm{P}$ NMR Line-Broadening Data for the Relatively Stable Co-POMs, $\alpha_{1}-C_{0} P_{2} W_{17}$, and $\alpha_{2}-C_{0} P_{2} W_{17}$. For the case of $\alpha_{1}-\mathrm{CoP}_{2} \mathrm{~W}_{17}$ and $\alpha_{2}-\mathrm{CoP}_{2} \mathrm{~W}_{17}$ at $\mathrm{pH}=5.8$ and 8.0 and because these Co-POMs appear to be relatively "stable" in initial $\mathrm{Co}(\mathrm{II})_{\mathrm{aq}}$ detection experiments, we conducted ${ }^{31} \mathrm{P}$ NMR experiments over a longer time scale, 7-10 h, Figure S12 of the Supporting Information. These longer time scale experiments show that at $\mathrm{pH}=5.8$ little change in the $\mathrm{Co}(\mathrm{II})_{\mathrm{aq}}$ beyond experimental error is observed. Addition of excess EDTA $(92 \mu \mathrm{M})$ to $\alpha_{1}-\mathrm{CoP}_{2} \mathrm{~W}_{17}$ and $\alpha_{2}-\mathrm{CoP}_{2} \mathrm{~W}_{17}$ at $\mathrm{pH}=5.8$ returns the ${ }^{31} \mathrm{P}$ NMR line width of $\mathrm{NaPi}$ to its natural width of $\sim 2 \mathrm{~Hz}$. Overall, the results teach that $\alpha_{1}-\mathrm{CoP}_{2} \mathrm{~W}_{17}$ and $\alpha_{2^{-}}$ $\mathrm{CoP}_{2} \mathrm{~W}_{17}$ contain from $\sim 0.25 \%$ to $\sim 1.5 \%$ of their $\mathrm{Co}(\mathrm{II})$ in solution, a level of $\mathrm{Co}$ (II) that could readily be explained by either a low level of $\mathrm{Co}$ (II) countercation impurity or $\mathrm{Co}$ (II) leaching (or a combination of these two). The bottom line is clear, however: detecting $\mathrm{Co}$ (II) that leads to $\mathrm{CoO}_{\mathrm{x}}$ or other possible catalyst species derived from the parent Co-POM is a $\leq \mu \mathrm{M}$ detection problem.

As for the $\mathrm{pH}=8.0$ experiments, observing the $\mathrm{Co}(\mathrm{II})_{\mathrm{aq}}$ concentration from $\alpha_{1}-\mathrm{CoP}_{2} \mathrm{~W}_{17}$ over longer time-scales (10 h) at $\mathrm{pH}=8.0$ demonstrates that the $\mathrm{Co}(\mathrm{II})_{\mathrm{aq}}$ concentration increases at a slow rate without plateauing-even after $10 \mathrm{~h}$. This indicates that $\mathrm{a}_{1}-\mathrm{CoP}_{2} \mathrm{~W}_{17}$ is unstable at $\mathrm{pH}=8.0$ and dissociating $\mathrm{Co}(\mathrm{II})_{\mathrm{aq}}$, Figure S12. Intriguingly, the $\mathrm{Co}(\mathrm{II})_{\mathrm{aq}}$ concentration from $\boldsymbol{\alpha}_{2}-\mathrm{CoP}_{2} \mathrm{~W}_{17}$ actually decreases over time in the pH 8.0 solution (Figures S11 and S12 of the Supporting Information). Possible explanations for this interesting observation, notably the possible consumption of $\mathrm{Co}$ (II) by the conceivable formation of $\mathrm{Co}_{4} \mathrm{P}_{4} \mathrm{~W}_{30}$, are discussed in the Supporting Information for the interested reader. ${ }^{55,56}$

To summarize the $\mathrm{Co}(\mathrm{II})_{\mathrm{aq}}$-induced ${ }^{31} \mathrm{P}$ NMR line-broadening experiments, all of the Co-POMs examined show nonzero detectable amounts of $\mathrm{Co}(\mathrm{II})_{\mathrm{aq}}$ under the buffer conditions specified. The amount of $\mathrm{Co}(\mathrm{III})_{\mathrm{aq}}$ released into solution ranges from $\sim 0.25 \%$ to $50 \%$ of the total cobalt in $0.1 \mathrm{M} \mathrm{NaPi} \mathrm{pH} \mathrm{=}$ 5.8 and 8.0. Furthermore, due to the large molecular mass of the Co-POMs, cobalt elemental analysis is insufficient to quantify $\mathrm{Co}$ (II) present as a countercation and at the low levels that can matter for WOCatalysis by electrode bound and formed $\mathrm{CoO}_{\mathrm{x}}$. However, $\mathrm{Co}(\mathrm{II})_{\mathrm{aq}}$-induced line broadening of the ${ }^{31} \mathrm{P}$ NMR peak of NaPi is a much more useful, powerful, and relatively direct technique to quantify the amount of $\mathrm{Co}(\mathrm{II})_{\mathrm{aq}}$ either leached into solution, or present initially as a $\mathrm{Co}$ (II) counterion impurity from syntheses employing Co(II).

Stability of the Co-POMs-cathodic Stripping. Because ${ }^{11} \mathrm{~B}$ is a quadrupolar nucleus with relative receptivity of 0.165 compared to ${ }^{1} \mathrm{H}$, and perhaps also because borate buffer has a complex speciation (especially near its $\mathrm{pK}_{\mathrm{a}}$, with at least 5 boron species being present), ${ }^{54} \mathrm{Co}(\mathrm{II})_{\mathrm{aq}}$-induced ${ }^{11} \mathrm{~B} \mathrm{NMR}$ line broadening is unknown at present. Hence, to measure the amount of $\mathrm{Co}(\mathrm{II})_{\mathrm{aq}}$ that leaches from the Co-POMs after $3 \mathrm{~h}$ of aging in $0.1 \mathrm{M} \mathrm{NaB} \mathrm{pH} 9.0$ buffer, cathodic stripping was employed as the most convenient, sensitive, and selective method presently available for the NaB buffer systems.

The results of the cathodic stripping studies are summarized in Figure 3 and Table 1. The amount of $\mathrm{Co}(\mathrm{II})_{\mathrm{aq}}$ detected for the six prototype Co-POMs by ${ }^{31} \mathrm{P}$ NMR at $\mathrm{pH} 5.8$ and 8.0 are also summarized in Table 1 for comparison. The amount of $\mathrm{Co}(\mathrm{II})_{\mathrm{aq}}$ detected by cathodic stripping for the $0.1 \mathrm{M} \mathrm{NaPi} \mathrm{pH}$ $=8.0$ conditions proved to be the same within experimental error to the $\mathrm{Co}(\mathrm{II})_{\mathrm{aq}}$ detected by ${ }^{31} \mathrm{P} \mathrm{NMR}$ (the error bars are much larger for cathodic stripping, that method often 
Table 1. Comparison of the Leached Co(II) $)_{\mathrm{aq}}(\mu \mathrm{M})$ after $3 \mathrm{~h}$ of Solution Aging from $500 \mu \mathrm{M}$ Co-POM Solutions under the Three Buffer Conditions (Values Shown in Bold in Parentheses are the Percent of Cobalt That Has Dissociated from the Co-POM Compared to the Total Cobalt Present Initially in the Co-POM) ${ }^{\mathrm{a}}$

\begin{tabular}{|c|c|c|c|}
\hline \multirow[b]{2}{*}{ polyoxometalate } & \multicolumn{2}{|c|}{$\begin{array}{c}{\left[\mathrm{Co}(\mathrm{II})_{\mathrm{aq}}\right] \text { by }{ }^{31} \mathrm{P} \text { NMR, } \mu \mathrm{M}(\%} \\
\mathrm{Co}(\mathrm{II}) \text { after } 3 \mathrm{~h})\end{array}$} & \multirow{2}{*}{$\begin{array}{c}{\left[\mathrm{Co}(\mathrm{III})_{\mathrm{aq}}\right] \text { by }} \\
\text { cathodic stripping, } \\
\mu \mathrm{M}(\% \mathrm{Co}(\mathrm{II}) \\
\text { after } 3 \mathrm{~h})\end{array}$} \\
\hline & $\begin{array}{l}0.1 \mathrm{M} \mathrm{NaPi} \mathrm{pH} \\
5.8 \text { [data range] }\end{array}$ & $\begin{array}{l}0.1 \mathrm{M} \mathrm{NaPi} \mathrm{pH} \\
8.0 \text { [data range] }\end{array}$ & \\
\hline $\mathrm{Co}_{4} \mathrm{P}_{2} \mathrm{~W}_{18}$ & $\begin{array}{c}11 \pm 3 \\
(0.5 \pm 0.2 \%) \\
{[8-15]}\end{array}$ & $\begin{array}{c}55 \pm 3 \\
(2.8 \pm 0.3 \%) \\
{[52-58]}\end{array}$ & $\begin{array}{c}44 \pm 5 \\
(2.2 \pm 0.3 \%) \\
{[38-49]}\end{array}$ \\
\hline $\mathrm{Co}_{9} \mathrm{P}_{5} \mathrm{~W}_{27}$ & $\begin{array}{c}75 \pm 2 \\
(1.7 \pm 0.1 \%) \\
{[73-77]}\end{array}$ & $\begin{array}{c}37 \pm 2 \\
(0.8 \pm 0.1 \%) \\
{[35-39]}\end{array}$ & $\begin{array}{c}44 \pm 5 \\
(1.0 \pm 0.1 \%) \\
{[39-50]}\end{array}$ \\
\hline $\mathrm{Co}_{4} \mathrm{P}_{4} \mathrm{~W}_{30}$ & $\begin{array}{c}62 \pm 3 \\
(3.1 \pm 0.4 \%) \\
{[59-66]}\end{array}$ & $\begin{array}{c}79 \pm 3 \\
(3.9 \pm 0.1 \%) \\
{[77-82]}\end{array}$ & $\begin{array}{c}170 \pm 20 \\
(9 \pm 1 \%) \\
{[150-192]}\end{array}$ \\
\hline $\mathrm{CoPW}_{11}$ & $\begin{array}{c}6 \pm 3 \\
(1.3 \pm 0.6 \%) \\
{[3-9]}\end{array}$ & $\begin{array}{c}247 \pm 3 \\
(50 \pm 5 \%) \\
{[245-250]}\end{array}$ & $\begin{array}{l}440 \pm 50 \\
(90 \pm 10 \%) \\
{[390-490]}\end{array}$ \\
\hline $\mathrm{a}_{1}-\mathrm{CoP}_{2} \mathrm{~W}_{17}$ & $\begin{array}{c}1.2 \pm 0.3 \\
(0.25 \pm 0.06 \%)^{\mathrm{b}} \\
{[0.8-1.4]^{\mathrm{b}}}\end{array}$ & $\begin{array}{c}6 \pm 3 \\
(1.2 \pm 0.6 \%) \\
{[3-9]}\end{array}$ & $\begin{array}{c}33 \pm 5 \\
(6.6 \pm 0.6 \%) \\
{[29-38]}\end{array}$ \\
\hline $\mathrm{\alpha}_{2}-\mathrm{CoP}_{2} \mathrm{~W}_{17}$ & $\begin{array}{c}7.7 \pm 3 \\
(1.5 \pm 0.6 \%)\end{array}$ & $\begin{array}{c}10 \pm 3 \\
(1.9 \pm 0.6 \%)\end{array}$ & $\begin{array}{c}97 \pm 9 \\
(19 \pm 2 \%)\end{array}$ \\
\hline & {$[4-11]$} & {$[7-12]$} & [88-106] \\
\hline
\end{tabular}

${ }^{\mathrm{a}}$ The $\mathrm{Co}(\mathrm{II})_{\mathrm{aq}}$ values in $0.1 \mathrm{M} \mathrm{NaPi}$ at $\mathrm{pH} 5.8$ and 8.0 were determined using $\mathrm{Co}(\mathrm{II})_{\mathrm{aq}}$-induced line broadening ${ }^{31} \mathrm{P}$ NMR. The $\mathrm{Co}(\mathrm{II})_{\mathrm{aq}}$ values in $0.1 \mathrm{M} \mathrm{NaB} \mathrm{pH} 9.0$ were determined using cathodic stripping. ${ }^{b}$ Values obtained for $\mathrm{a}_{\Gamma} \mathrm{CoP}_{2} \mathrm{~W}_{17}$ are with the third, more precise, lower concentration $\mathrm{Co}(\mathrm{II})_{\mathrm{aq}}$ calibration curve described in the Experimental Section, a calibration curve designed and conducted specifically for this lowest detected $\mathrm{Co}(\mathrm{II})_{\mathrm{aq}}$ value.

complicated by $\mathrm{W}$ reduction waves in the differential pulse voltammetry).

The results in Table 1 further demonstrate that all of the CoPOMs show some detectable $\mathrm{Co}(\mathrm{II})_{\mathrm{aq}}$ under any of the conditions examined, ranging from $\sim 0.25 \%$ to now $\sim 90 \%$ of the total cobalt present initially in the Co-POMs in the more basic, $\mathrm{pH}=9.0$ solution. Additionally, clear solution $\mathrm{pH}$ dependent trends are apparent for each Co-POM, Table 1. For example, after $3 \mathrm{~h}$ the relatively stable $\mathrm{CoPW}_{11}$ dissociates just $1.3( \pm 0.6) \%$ of its $\mathrm{Co}(\mathrm{II})$ in $\mathrm{pH} 5.8$, but dissociates $50( \pm 5)$ and $90( \pm 10) \%$ of its $\mathrm{Co}(\mathrm{II})$ in $\mathrm{pH} 8.0$ and 9.0 solution, respectively. The $\mathrm{pH}$ stability of $\mathrm{CoPW}_{11}$ makes sense considering that the synthesis of $\mathrm{CoPW}_{11}$ relies on the partial degradation of the parent $\mathrm{PW}_{12} \mathrm{O}_{40}{ }^{3-}$ Keggin ion at $\mathrm{pH} \sim 5^{38}$ (the parent $\mathrm{PW}_{12} \mathrm{O}_{40}{ }^{3-}$ itself being prepared using concentrated $\mathrm{HCl}^{36}$ ). Hence, $\mathrm{CoPW}{ }_{11}$ is more stable at the mildly acidic pH 5.8 NaPi buffer employed and then is as expected to be less stable at the higher $\mathrm{pH} 8-9$ values.

Overall, our results reiterate an undeniable fact about $\mathrm{Co}_{0}$ POMs, namely that $\mathrm{Co}-\mathrm{POM}$ precatalysts cannot be generally described as 100\% "stable" over time under a variety of common buffer and aqueous, ${ }^{25}$ WOCatalysis and $\mathrm{pH}$ conditions, at least as judged by whether or not $\mathrm{Co}(\mathrm{II})_{\mathrm{aq}}$ is detectable at the $\sim 0.25 \%$ or higher, $\mu \mathrm{M}$ level. Instead, each of $\mathrm{Co}_{4} \mathrm{P}_{2} \mathrm{~W}_{18}$, $\mathrm{Co}_{9} \mathrm{P}_{5} \mathrm{~W}_{27}, \mathrm{Co}_{4} \mathrm{P}_{4} \mathrm{~W}_{30}, \mathrm{CoPW}_{11}, \mathrm{a}_{1}-\mathrm{CoP}_{2} \mathrm{~W}_{17}$, and $\mathrm{a}_{2}-$ $\mathrm{CoP}_{2} \mathrm{~W}_{17}$ show somewhere between the limits seen of $\sim 0.25-\sim 50 \%$ detectable $\mathrm{Co}(\mathrm{II})_{\mathrm{aq}}$ in $0.1 \mathrm{M}, \mathrm{NaPi} \mathrm{pH}=5.8$ or 8.0 and up to $\sim 90 \% \mathrm{Co}$ (II) leaching in $\mathrm{NaB} \mathrm{pH}=9.0$ buffer solutions. The percentage of the WOCatalysis observed that can, therefore, be attributed to $\mathrm{CoO}_{x}$ formed from even those trace levels of $\mathrm{Co}(\mathrm{II})_{\mathrm{aq}}$ has to be carefully examined to answer the question of if the observed WOCatalysis is by the intact, molecular Co-POM or the often low-level amount of, however, high activity $\mathrm{CoO}_{\mathrm{x}}$ formed by even trace levels of $\mathrm{Co}(\mathrm{II})_{\mathrm{aq}}$.

WOCatalysis Activity: Confirming the Anodic Current Is Due to Water Oxidation. To ensure that the anodic current being observed is from water oxidation, and not some other process such as oxidation of the glassy carbon electrode (which has been observed in potentials greater than $+1.4 \mathrm{~V} \mathrm{vs}$ $\mathrm{Ag} / \mathrm{AgCl}),{ }^{28}$ we quantified the $\mathrm{O}_{2}$ produced under standard conditions of $500 \mu \mathrm{M}$ Co-POM aged $3 \mathrm{~h}$ or $\mathrm{Co}\left(\mathrm{NO}_{3}\right)_{2}(6-$ $500 \mu \mathrm{M}), 0.1 \mathrm{M} \mathrm{NaPi} \mathrm{pH}=5.8$ or 8.0 , and $\mathrm{NaB} \mathrm{pH}=9.0$ and at $1.1 \mathrm{~V}$ vs $\mathrm{Ag} / \mathrm{AgCl}$ for $5 \mathrm{~min}$. The theoretical $\mathrm{O}_{2}$ yield for each electrolysis experiment was calculated by dividing the total charge passed in coulombs (determined by integrating the current over time) by the charge of an electron $\left(1.602 \times 10^{-19}\right.$ $\mathrm{C} / \mathrm{e}^{-}$) and using the stoichiometry of $4 \mathrm{e}^{-}$passed per each $1 \mathrm{O}_{2}$ produced. The $\mathrm{O}_{2}$ concentration was monitored using an Ocean Optics NEOFOX $\mathrm{O}_{2}$-detection probe. By dividing the measured $\mathrm{O}_{2}$ yield at the end of the reaction by the theoretical $\mathrm{O}_{2}$ yield, the Faradaic efficiency of the reaction was also determined.

The observed Faradaic efficiency ranged from 80 to $100 \%$ in all cases. Additionally, a ca. $8 \%$ decline in the detected $\mathrm{O}_{2}$ concentration over a $\sim 1 \min$ period after the electrolysis is stopped is almost surely due to $\mathrm{O}_{2}$ equilibration with the reaction vessel's (minimized) headspace or possibly some escape from the electrochemical cell. In short, the Faradaic efficiency of $\mathrm{O}_{2}$ production is at least $\geq 80-100 \%$, and because of this, the anodic current can be used as a semiquantitative metric to compare WOCatalysis activity of the Co-POMs and authentic $\mathrm{CoO}_{x}$ (i.e., and to within a $\pm<20 \%$ error), more than sufficient for any of the conclusions reached in the present work.

WOCatalysis Activity: $\mathrm{O}_{2}$ Evolution from Co-POMs in Comparison with the Amount of $\mathrm{Co}(\mathrm{II})_{\mathrm{aq}}$ Released. Constant potential electrolysis was conducted on $3 \mathrm{~h}$ aged 500 $\mu \mathrm{M}$ solutions of the Co-POMs and $\mathrm{Co}\left(\mathrm{NO}_{3}\right)_{2}$ in each of the buffer conditions. The $\mathrm{Co}\left(\mathrm{NO}_{3}\right)_{2}$ concentrations chosen to compare with each Co-POM were based upon the amount of $\mathrm{Co}(\mathrm{II})_{\mathrm{aq}}$ that was detected in each buffer condition, Table 1, vide supra. The $\mathrm{O}_{2}$ produced by each Co-POM is summarized in Table S2 of the Supporting Information. The amount of WOCatalysis activity that can be attributed to $\mathrm{Co}(\mathrm{II})_{\mathrm{aq}}$ is shown in Table 2, in which the $\mathrm{O}_{2}$ yield from $\mathrm{Co}(\mathrm{II})_{\mathrm{aq}}$ is divided by the $\mathrm{O}_{2}$ yield from the Co-POM (eq 2). A value of $100 \%$ (or more) means that all of the catalysis can quantitatively accounted for by $\mathrm{Co}(\mathrm{II})_{\mathrm{aq}}$. For example, the percentage of WOCatalysis activity that can be attributed to $\mathrm{Co}(\mathrm{II})_{\mathrm{aq}}$ for $\mathrm{Co}_{4} \mathrm{P}_{2} \mathrm{~W}_{18}$ in $\mathrm{NaPi} \mathrm{pH}=8.0$ is $150 \pm 50 \%$. Such values near or $>100 \%$ mean that the $\mathrm{Co}(\mathrm{II})_{\mathrm{aq}}$ present is able to account for all of the WOCatalysis under those specific conditions.

$\%$ of WOCatalysis contributable to $\mathrm{Co}(\mathrm{II})_{\mathrm{aq}}$

$$
=\frac{\mathrm{O}_{2} \text { yield from } \mathrm{Co}(\mathrm{II})_{\mathrm{aq}}}{\mathrm{O}_{2} \text { yield from } \mathrm{Co}-\mathrm{POM}} \times 100
$$

Values significantly above $100 \%$ (e.g., for $\boldsymbol{\alpha}_{2}-\mathrm{CoP}_{2} \mathrm{~W}_{17}$ at $\mathrm{pH}$ $9.0,800 \pm 300 \%$, Table 2) indicate that the equivalent amount 
Table 2. Percent of WOCatalysis Activity That Can Be Accounted for by $\mathrm{Co}(\mathrm{II})_{\mathrm{aq}}$ for the Co-POMs under Each Buffer Condition $^{\mathrm{a}}$

\begin{tabular}{cccc} 
& \multicolumn{3}{c}{ buffer system } \\
\cline { 2 - 4 } polyoxometalate & $0.1 \mathrm{M} \mathrm{NaPi} \mathrm{pH}$ & $0.1 \mathrm{M} \mathrm{NaPi} \mathrm{pH}$ & $0.1 \mathrm{M} \mathrm{NaB} \mathrm{pH}$ \\
$\mathrm{Co}_{4} \mathrm{P}_{2} \mathrm{~W}_{18}$ & $60 \pm 30 \%$ & $150 \pm 50 \% \%$ & $400 \pm 200 \%$ \\
$\mathrm{Co}_{9} \mathrm{P}_{5} \mathrm{~W}_{27}$ & $70 \pm 60 \%$ & $96 \pm 24$ & $300 \pm 200 \%$ \\
$\mathrm{Co}_{4} \mathrm{P}_{4} \mathrm{~W}_{30}$ & $60 \pm 40 \%$ & $140 \pm 70 \%$ & $140 \pm 70 \%$ \\
$\mathrm{CoPW}_{11}$ & $20 \pm 20 \%$ & $180 \pm 40 \%$ & $100 \pm 40 \%$ \\
$\alpha_{1}-\mathrm{CoP}_{2} \mathrm{~W}_{17}$ & $16 \pm 6 \% \mathrm{~b}$ & $90 \pm 30 \%$ & $350 \pm 40 \%$ \\
$\mathrm{a}_{2}-\mathrm{CoP}_{2} \mathrm{~W}_{17}$ & $60 \pm 60 \%$ & $90 \pm 50 \%$ & $800 \pm 300 \%$
\end{tabular}

${ }^{\mathrm{a}}$ The Co-POMs $(500 \mu \mathrm{M})$ were aged for $3 \mathrm{~h}$ under each buffer condition. Electrolysis was then conducted at $1.1 \mathrm{~V} \mathrm{vs} \mathrm{Ag/AgCl}$. The $\mathrm{O}_{2}$ yield $(\mu \mathrm{mol})$ was determined as described in the text and is listed in Table S2 of the Supporting Information. To compare with the amount of $\mathrm{Co}(\mathrm{II})_{\mathrm{aq}}$ that is leached, $\mathrm{Co}\left(\mathrm{NO}_{3}\right)_{2}$ was used in the concentrations determined and the amounts are summarized in Table 1. The amount of $\mathrm{O}_{2}$ produced from the $\mathrm{Co}(\mathrm{II})_{\mathrm{aq}}$ was divided by the amount of $\mathrm{O}_{2}$ produced from the Co-POMs to determine the percent of WOCatalysis activity that can be accounted for by the $\mathrm{Co}(\mathrm{II})_{\mathrm{aq}}$ present. ${ }^{b}$ Data obtained using the third, lower $\mathrm{Co}(\mathrm{II})_{\mathrm{aq}}$ calibration curve described in the Experimental Section and designed specifically for the $\mathrm{a}_{1}-\mathrm{CoP}_{2} \mathrm{~W}_{17}$ POM system.

of $\mathrm{Co}(\mathrm{II})_{\mathrm{aq}}$ that is detected after $3 \mathrm{~h}$ has a greater WOCatalysis activity than the films generated from Co-POMs. The $\gg 100 \%$ values are interesting, and suggest several possible interpretations, including: (i) that the Co-POM somehow poisons $\mathrm{CoO}_{\mathrm{x}}$ films made from $\mathrm{Co}(\mathrm{II})_{\mathrm{aq}}$ in the presence of Co-POMs (indeed, evidence of $\mathrm{W}$ incorporation is demonstrated in some Co-POM derived films, vide infra); (ii) that the $\mathrm{NO}_{3}{ }^{-}$ somehow enhances the catalysis in $\mathrm{CoO}_{x}$ made from $\mathrm{Co}\left(\mathrm{NO}_{3}\right)_{2}$; (iii) that the $\mathrm{Co}(\mathrm{II})_{\mathrm{aq}}$ values determined by ${ }^{31} \mathrm{P}$ NMR or cathodic stripping are somewhat higher than the true $\mathrm{Co}(\mathrm{II})_{\mathrm{aq}}$ values; or possibly (iv) that the film formation (and, for example, the surface area and number of active sites) is affected by the $\mathrm{pH}^{54}$ or the presence of POMs, which in turn affects the observed WOCatalysis. However, the most obvious, and most important, conclusion is $(\mathrm{v})$ that $\mathrm{CoO}_{\mathrm{x}}$ formed from at least $\mathrm{Co}^{\mathrm{II}}\left(\mathrm{NO}_{3}\right)_{2}$ is a better WOCatalyst at $\mathrm{pH} 8$ and 9 than any of the Co-POMs tested.

Values $\ll 100 \%$ are also of considerable interest because they are consistent with molecular, homogeneous Co-POM WOCatalysis or conceivably consistent with some other, presently unknown, ostensibly homogeneous catalyst derived from the Co-POM (alternative hypothesis \#5 from Scheme 1). However, considering that both $\mathrm{CoPW}_{11}$ and $\boldsymbol{\alpha}_{1}-\mathrm{CoP}_{2} \mathrm{~W}_{17}$ are stable in $\mathrm{NaPi} \mathrm{pH}=5.8$ (decomposing by $1.3 \%$ and $0.25 \%$, respectively, at this $\mathrm{pH}$ ), and given that the decomposition byproduct detected is $\mathrm{Co}(\mathrm{II})_{\mathrm{aq}}$ and (by mass balance) the lacunary $\mathrm{PW}_{11} \mathrm{O}_{39}{ }^{7-}$ and $\left[\mathrm{\alpha}_{1}-\mathrm{P}_{2} \mathrm{~W}_{17} \mathrm{O}_{61}\right]^{10-}$ (which do not contain oxidizable metals that can serve as at least facile WOCatalysts), the simplest (Ockham's razor) interpretation of the $\ll 100 \%$ data is that the intact $\mathrm{CoPW}_{11}$ and $\alpha_{1}-\mathrm{CoP}_{2} \mathrm{~W}_{17}$ are the dominant WOCatalysts under those specific $\mathrm{pH} 5.8$ $\mathrm{NaPi}$ conditions. For example, the percentage of WOCatalysis activity that can be attributed to $\mathrm{Co}(\mathrm{II})_{\mathrm{aq}}$ for $\mathrm{CoPW}_{11}$ and $\mathrm{\alpha}_{1-}$ $\mathrm{CoP}_{2} \mathrm{~W}_{17}$ in $\mathrm{NaPi} \mathrm{pH}=5.8$ is $20( \pm 20) \%$ and $16( \pm 6 \%)$, respectively. These data, in turn, imply that intact $\mathrm{CoPW}_{11}$ and $\alpha_{1}-C_{0} \mathrm{P}_{2} \mathrm{~W}_{17}$ are the dominant electrochemically driven WOCatalyst at $\mathrm{pH}=5.8$ for $80( \pm 20) \%$ and $84( \pm 6) \%$ of the observed current. In short, the $\ll 100 \%$ data in Table 2 are consistent with if not strongly supportive of the interpretation that the most stable Co-POMs examined, $\mathrm{CoPW}_{11}$ and $\boldsymbol{\alpha}_{1^{-}}$ $\mathrm{CoP}_{2} \mathrm{~W}_{17}$, are serving as electrochemically driven, molecular WOCatalysts, a previously unavailable, important conclusion given the controversy about when and where Co-POMs can be molecular WOCatalysts.

Looking more broadly at Table 2, there are several overarching trends in the data and even given the inherently large error bars in Table 2 (that derive from having to detect mere micromolar levels of $\mathrm{Co}(\mathrm{II})_{\mathrm{aq}}$ as discussed more in the Supporting Information): at lower $\mathrm{pH}$ the Co-POMs account for a greater amount of the WOCatalysis. At higher $\mathrm{pH}$ the WOCatalysis current from $\mathrm{Co}(\mathrm{II})_{\mathrm{aq}}$ becomes increasingly prevalent, with $\mathrm{Co}$ (II) accounting for $\geq 100 \%$ of the observed WOCatalysis activity. This $\mathrm{pH}$ trend in $\mathrm{Co}(\mathrm{II})_{\mathrm{aq}}$ contribution to WOCatalysis activity makes sense considering that the CoPOMs examined are often (although not always) more stable at the lower $\mathrm{pH}$, for example, $\mathrm{CoPW}_{11}$ decomposes by only $1.3( \pm 0.6) \%$ at $\mathrm{pH} 5.8$ but decomposes by $50( \pm 5) \%$ and $90( \pm 10) \%$ at $\mathrm{pH} 8.0$ and 9.0 , respectively. Hence, unsurprisingly, the Co-POMs examined are more likely to be intact WOCatalyst under conditions where they are demonstrably more stable, $\mathrm{pH}$ values closer to the $\mathrm{pHs}$ at which they form and are synthesized. Also worth noting here is that the $\mathrm{CoO}_{\mathrm{x}}$ catalyst is also affected by $\mathrm{pH}$ as previously reported, ${ }^{57}$ with $\mathrm{CoO}_{\mathrm{x}}$ being more active at higher $\mathrm{pH}$, and not being stable below $\mathrm{pH}=3.5^{57}$

Greater WOCatalysis Activity of $\mathrm{CoO}_{x}$ Compared to That of the Most Stable Co-POMs. Lastly, although our evidence supports $\mathrm{CoPW}_{11}$ and $\mathrm{\alpha}_{1}-\mathrm{CoP}_{2} \mathrm{~W}_{17}$ as homogeneous WOCatalysts at $\mathrm{pH}=5.8$, a critical point is that the $\mathrm{CoO}_{x}$ formed from the equivalent amount of $\mathrm{Co}(\mathrm{II})_{\mathrm{aq}}$ is an estimated $\sim 35-150$-fold faster WOCatalyst at $\mathrm{pH}=5.8$ than is the corresponding homogeneous Co-POM (as detailed in the Supporting Information). Even using the ranges and error bars on the data in Tables 1 and 2 to bias the estimate as much as possible in favor of the Co-POM as the catalyst (and then also for the single most stable Co-POM examined, $\alpha_{1^{-}}$ $\mathrm{CoP}_{2} \mathrm{~W}_{17}$ ) still yields the insight that $\mathrm{CoO}_{\mathrm{x}}$ formed from the released $\mathrm{Co}(\mathrm{II})_{\mathrm{aq}}$ is at least 35 -fold more active than $\alpha_{1^{-}}$ $\mathrm{CoP}_{2} \mathrm{~W}_{17}$ (see the Supporting Information for details).

If one does this same calculation for, again, the most stable $\mathrm{\alpha}_{1}-\mathrm{CoP}_{2} \mathrm{~W}_{17}$ but now at $\mathrm{pH}=8$, the $\mathrm{CoO}_{\mathrm{x}}$ is at least 80 -fold more active if (and if one again biases the calculation as much as the data allow in favor of Co-POM-based catalysis; see the Supporting Information for details of these estimates), and likely $\sim 740$-fold more active at $\mathrm{pH}=8$ (see the Supporting Information for the detailed calculations).

To summarize, comparing the WOCatalysis activity of the 3 $\mathrm{h}$ aged $\mathrm{Co}-\mathrm{POMs}$ with the amount of detected $\mathrm{Co}(\mathrm{II})_{\mathrm{aq}}$ reveals that at $\mathrm{pH}=8.0$ in $0.1 \mathrm{M} \mathrm{NaPi}$ and $\mathrm{pH}=9.0$ in $0.1 \mathrm{M} \mathrm{NaB}$ all of the six exemplary Co-POMs examined give rise to heterogeneous $\mathrm{CoO}_{\mathrm{x}}$ as the dominant WOCatalyst. However, at $\mathrm{pH}=5.8$ in $0.1 \mathrm{M} \mathrm{NaPi}$ and under electrochemically driven WOCatalysis conditions, the evidence strongly suggests that $\mathrm{CoPW}_{11}$ and $\mathrm{\alpha}_{1}-\mathrm{CoP}_{2} \mathrm{~W}_{17}$, and perhaps also $\mathrm{Co}_{4} \mathrm{P}_{2} \mathrm{~W}_{18}$ and $\mathrm{a}_{2}-\mathrm{CoP}_{2} \mathrm{~W}_{17}$, can serve as homogeneous, molecular WOCatalysts, albeit with $\mathrm{CoO}_{\mathrm{x}}$ being $\sim 35-150 \times$ faster at $\mathrm{pH}=5.8$ and, most likely, $\sim 740 \times$ faster at $\mathrm{pH}=8$ (numbers that can be refined using the methods herein if others require greater precision than reported). One key, unequivocal conclusion from the present studies is clear, however: $\mathrm{CoO}_{\mathrm{x}}$ is at least $\mathrm{a} \geq$ 10 -fold more active WOCatalys under electrochemical 
a) $\mathbf{C o}_{4} \mathbf{P}_{2} \mathbf{W}_{18}$ in $0.1 \mathrm{M} \mathrm{NaPi} \mathrm{pH} 8.0$

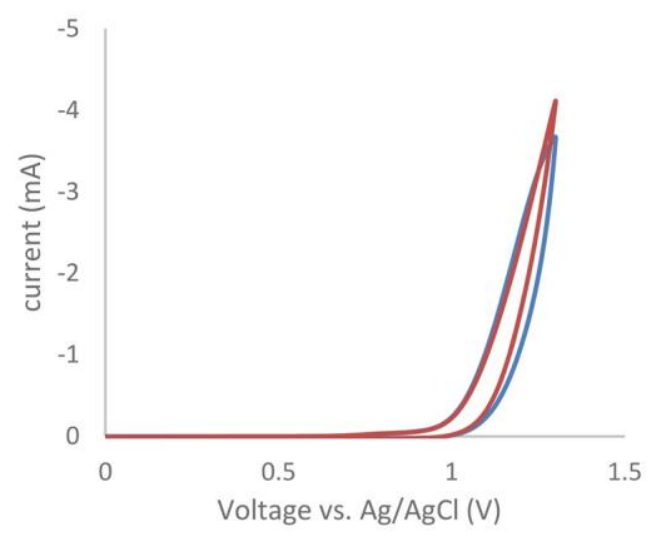

c) $\boldsymbol{\alpha}_{1}-\mathbf{C o P}_{2} \mathbf{W}_{17}$ in $0.1 \mathrm{M} \mathrm{NaPi}$ pH 5.8

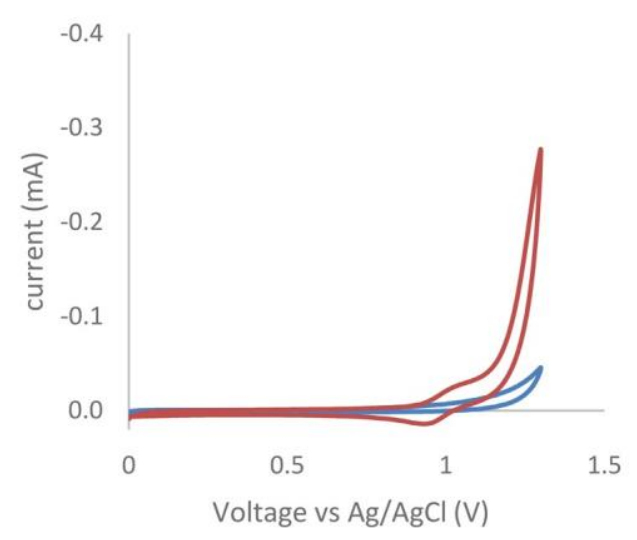

b) $\mathbf{C o}_{4} \mathbf{P}_{2} \mathbf{W}_{18}$ in $0.1 \mathrm{M} \mathrm{NaPi}$ pH $8.0 \mathrm{w} / \mathrm{EDTA}$

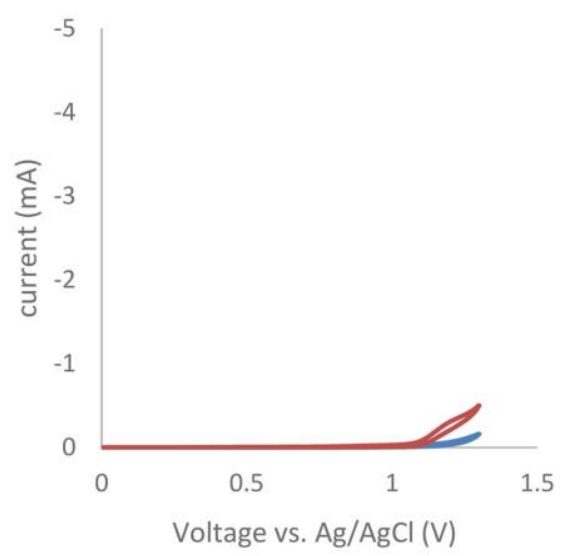

d) $\boldsymbol{\alpha}_{2}-\mathrm{CoP}_{2} \mathbf{W}_{17}$ in $0.1 \mathrm{M} \mathrm{NaPi} \mathrm{pH} 8.0$

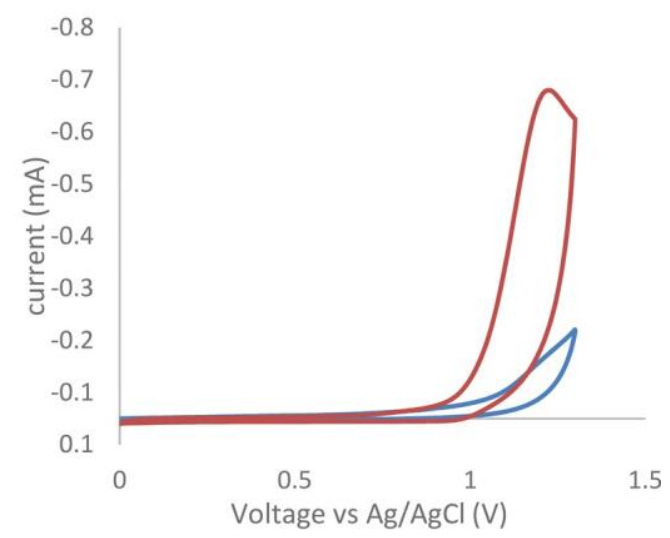

Figure 5. Selected CVs of electrodes after 5 min controlled potential electrolysis in the original Co-POM solution (red) and once the electrodes were removed, rinsed, and replaced into a fresh, buffer-only solution (blue): (a) $\mathrm{Co}_{4} \mathrm{P}_{2} \mathrm{~W}_{18}$ in $0.1 \mathrm{M} \mathrm{NaPi} \mathrm{pH} 8.0$; (b) $\mathrm{Co}_{4} \mathrm{P}_{2} \mathrm{~W}_{18}$ in $0.1 \mathrm{M} \mathrm{NaPi} \mathrm{pH}$ 8.0 with $120 \mu \mathrm{M}$ EDTA (2 equiv/Co(II) $)_{\mathrm{aq}}$ ); (c) $\alpha_{1}-\mathrm{CoP}_{2} \mathrm{~W}_{17}$ in $0.1 \mathrm{M} \mathrm{NaPi} \mathrm{pH} 5.8$; (d) $\alpha_{2}-\mathrm{CoP}_{2} \mathrm{~W}_{17}$ in $0.1 \mathrm{M} \mathrm{NaPi} \mathrm{pH}$ 8.0. The remainder of the $\mathrm{CVs}$ are shown in the Supporting Information.

conditions than any of the Co-POMs examined to date for any of the pHs $(5.8,8.0 .9 .0)$ and buffers examined.

Electrochemical Characterization of the Deposited Films. Previous studies have shown that electrode-bound heterogeneous $\mathrm{CoO}_{x}$ formed from aged Co-POM solutions is active toward WOCatalysis. ${ }^{23,27}$ Additionally, such $\mathrm{CoO}_{x}$ films remain active when the working electrode is removed from the original Co-POM solution and placed in a fresh, buffer-only solution, ${ }^{23,27}$ thereby providing a way to characterize what amount of the WOCatalysis current detected is attributable to the film.

Controls similar to those performed before ${ }^{23,27}$ were therefore conducted in which controlled potential electrolysis (5-30 min) was conducted in $500 \mu \mathrm{M}$ solutions of Co-POM that had been aged $3 \mathrm{~h}$. Cyclic voltammetry (CV) was then conducted first in the original Co-POM solution. The electrodes were subsequently removed, rinsed gently with water, replaced into a fresh, buffer-only solution, and a second $\mathrm{CV}$ was obtained. The resultant before and after $\mathrm{CVs}$ for selected Co-POMs are shown in Figure 5; the rest of the CVs for the Co-POMs and additional CV experiments are provided in Figure S13 Supporting Information. Figure 5a is a control demonstrating that the previously reported, known ${ }^{23,24}$ catalytically active film from $\mathrm{Co}_{4} \mathrm{P}_{2} \mathrm{~W}_{18}$ can be reproducibly formed as part of the present studies from a $500 \mu \mathrm{M}$ solution of $\mathrm{Co}_{4} \mathrm{P}_{2} \mathrm{~W}_{18}$ in $0.1 \mathrm{M} \mathrm{NaPi}$ at $\mathrm{pH} 8.0$ and after $3 \mathrm{~h}$ aging. Figure $5 \mathrm{~b}$ is a second control that tests the possibility raised previously $^{24}$ (but heretofore not tested) that $\mathrm{CoO}_{x}$ might directly form from Co-POMs as well as from $\mathrm{Co}(\mathrm{II})_{\mathrm{aq}}$ at sufficiently oxidizing potentials. Hence, the experiment reported in Figure $5 \mathrm{~b}$ also contains $500 \mu \mathrm{M} \mathrm{Co} \mathrm{Co}_{4} \mathrm{P}_{2} \mathrm{~W}_{18}$ in $0.1 \mathrm{M} \mathrm{NaPi}$ at $\mathrm{pH} 8.0$ that has aged $3 \mathrm{~h}$, but now has been spiked after aging with $120 \mu \mathrm{M}$ EDTA to chelate the free $\sim 60$ $\mu \mathrm{M} \mathrm{Co}(\mathrm{II})_{\mathrm{aq}}$ known to be formed. Almost all of the WOCatalysis activity is diminished, and no significant film is formed, implying that $\mathrm{Co}_{4} \mathrm{P}_{2} \mathrm{~W}_{18}$ does not serve as a direct precursor to $\mathrm{CoO}_{\mathrm{x}}$ at $\mathrm{pH} 8.0$, thereby disproving hypothesis \#4 from Scheme 1.

The CVs shown in Figure 5c,d present the CVs after electrolysis in the original buffer solution and then in a bufferonly solution for $\alpha_{1}-\mathrm{CoP}_{2} \mathrm{~W}_{17}$ in $0.1 \mathrm{M} \mathrm{NaPi}$ at $\mathrm{pH} 5.8$ and $\alpha_{2^{-}}$ $\mathrm{CoP}_{2} \mathrm{~W}_{17}$ in $0.1 \mathrm{M} \mathrm{NaPi}$ at $\mathrm{pH} 8.0$, respectively (both after $3 \mathrm{~h}$ of solution aging). The significantly higher current and unique $\mathrm{CV}$ features of the original Co-POM solution, vs those for the rinsed electrode replaced into buffer-only solution $\mathrm{CV}$, provide additional evidence for a solution-based species having a role in the observed WOCatalysis for $\alpha_{1}-\mathrm{CoP}_{2} \mathrm{~W}_{17}, \mathrm{\alpha}_{2}-\mathrm{CoP}_{2} \mathrm{~W}_{17}$, and $\mathrm{CoPW}_{11}$. The Ockham's razor based hypothesis is that, under conditions where a Co-POM such as $\alpha_{1}-\mathrm{CoP}_{2} \mathrm{~W}_{17}$ in $0.1 \mathrm{M}$ $\mathrm{NaPi}$ at $\mathrm{pH} 5.8$ is relatively stable (less than $2 \%$ detectable 

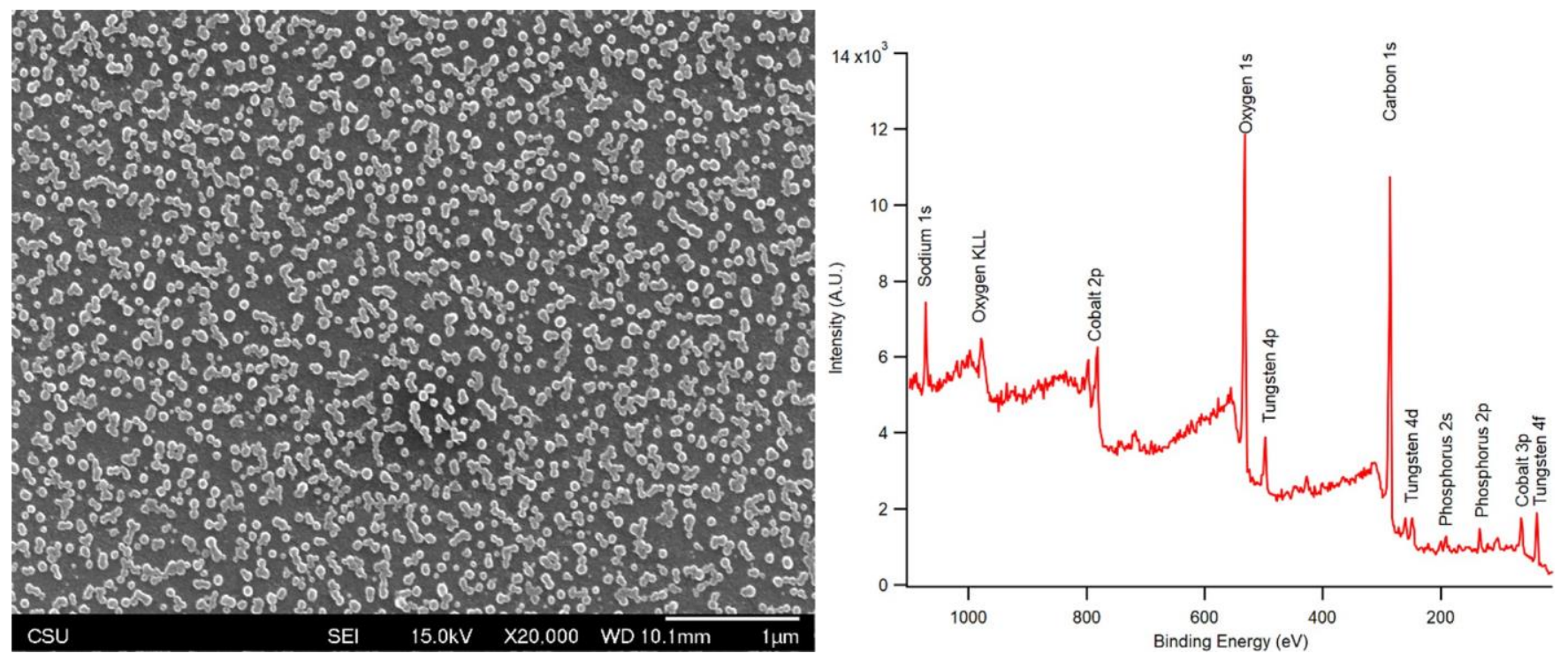

Figure 6. SEM micrograph (left) and XPS (right) of electrodes after 30 min bulk electrolysis from a $3 \mathrm{~h}$ aged solution of $500 \mu \mathrm{M} \mathrm{a}_{2}$-CoP $\mathrm{W}_{17}$ in $0.1 \mathrm{M} \mathrm{NaPi} \mathrm{pH}$ 8.0. The globular nature of the film is similar to previously observed films from Co(II) or Co-POMs. ${ }^{8,23,26}$ The i vs $t$ curve for the film deposition is presented in Figure S14 of the Supporting Information.

$\left.\mathrm{Co}(\mathrm{II})_{\mathrm{aq}}\right)$, the $\mathrm{a}_{1}-\mathrm{CoP}_{2} \mathrm{~W}_{17}$ is serving as a molecular, homogeneous WOCatalysts-albeit one with $\geq 10 \times$ lower WOCatalysis current than the $\mathrm{CoO}_{x}$ films formed from the less stable Co-POMs (Table S2).

In summary, electrolysis and $\mathrm{CV}$ of the electrodes in the electrolyzed solutions (red traces in Figure 5 and Figure S13 of the Supporting Information) followed by electrolysis in bufferonly solutions (blue traces in Figure 5 and Figure S13 of the Supporting Information) helps illuminate whether the active catalyst is a solution-based species or an electrode bound species. The results are in good agreement with the percent WOCatalysis activity from the previous section. For example, at $\mathrm{pH} 5.8$ the percent WOCatalysis evidence suggests that $\mathrm{Co}_{4} \mathrm{P}_{2} \mathrm{~W}_{18}, \mathrm{CoPW}_{11}, \alpha_{1}-\mathrm{CoP}_{2} \mathrm{~W}_{17}$, and $\mathrm{\alpha}_{2}-\mathrm{CoP}_{2} \mathrm{~W}_{17}$ can serve as molecular, homogeneous WOCatalyst. The CVs for those Co-POMs in $\mathrm{pH} 5.8$ provide additional evidence in support of a solution-based WOCatalyst (Figure 5 and Figure S13 of the Supporting Information). Other Co-POMs that show evidence of a solution-based WOCatalyst in $\mathrm{NaPi}$ at $\mathrm{pH}=8.0$ are $\mathrm{Co}_{9} \mathrm{P}_{5} \mathrm{~W}_{27}, \alpha_{1}-\mathrm{CoP}_{2} \mathrm{~W}_{17}$, and $\alpha_{2}-\mathrm{CoP}_{2} \mathrm{~W}_{17}$, whereas in $\mathrm{NaB}$ $\mathrm{pH}=9.0$ only $\mathrm{a}_{1}-\mathrm{CoP}_{2} \mathrm{~W}_{17}$ exhibits evidence of a solutionbased WOCatalyst (Figure 5 and Figure S13 of the Supporting Information). Note that although at $\mathrm{pH}=9.0$ the $\mathrm{CVs}$ of $\mathrm{Co}_{9} \mathrm{P}_{5} \mathrm{~W}_{27}, \alpha_{1}-\mathrm{CoP}_{2} \mathrm{~W}_{17}$, and $\alpha_{2}-\mathrm{CoP}_{2} \mathrm{~W}_{17}$ at $\mathrm{pH}=8.0$ and $\alpha_{1}-$ $\mathrm{CoP}_{2} \mathrm{~W}_{17}$ provide evidence of a solution-based WOCatalyst, the results in Table 2 provide evidence that under those at $\mathrm{pH}$ $=9.0$ conditions, $\mathrm{CoO}_{\mathrm{x}}$ is still the dominant WOCatalyst.

Morphological and Compositional Characterization of Deposited Films. Most of the Co-POMs showed an increase in WOCatalysis activity for longer electrolysis times, which is characteristic of $\mathrm{CoO}_{x}$ film deposition (Figure $\mathrm{S} 14$ of the Supporting Information)., ${ }^{8,23}$ Hence, we conducted electrolysis for $30 \mathrm{~min}$ to allow film accumulation and then dried the films for SEM and XPS characterization.

Figure 6 shows a typical electrode-bound film of globular particles that are formed from $3 \mathrm{~h}$ aged solutions of $500 \mu \mathrm{M}$ $\mathrm{a}_{2}-\mathrm{CoP}_{2} \mathrm{~W}_{17}$ in $0.1 \mathrm{M} \mathrm{NaPi} \mathrm{pH}$ 8.0. The XPS of the film from $\mathrm{\alpha}_{2}-\mathrm{CoP}_{2} \mathrm{~W}_{17}$ contains carbon (from the glassy carbon substrate), oxygen, cobalt, sodium, phosphorus, and tungsten,
Figure 6 (right). The $\mathrm{Co} / \mathrm{W}$ atom ratio from the highresolution XPS scans was determined to be 2.1:1.3, whereas the $\mathrm{Co} / \mathrm{W}$ ratio in the structure is $1: 17$, meaning that although $\mathrm{W}$ incorporation does occur, the original Co-POM is not a major component. This experiment was reproduced twice and similar XPS spectra were obtained, demonstrating reproducible W incorporation into $\mathrm{CoO}_{\mathrm{x}}$ films produced from $500 \mu \mathrm{M} \mathrm{a}_{2}-$ $\mathrm{CoP}_{2} \mathrm{~W}_{17}$ in $0.1 \mathrm{M} \mathrm{NaPi} \mathrm{pH}$ 8.0. Relevant here is that $\mathrm{W}$ incorporation into $\mathrm{CoO}_{x}$ films formed in the presence of aqueous $\mathrm{Na}_{2} \mathrm{WO}_{4}$ are both known and exhibit different WOC activity than seen for pure $\mathrm{CoO}_{x}$ films formed from just $\mathrm{Co}$ (II) in the absence of $\mathrm{W}^{58}$ The presence of tungsten in films formed from $\mathrm{a}_{2}-\mathrm{CoP}_{2} \mathrm{~W}_{17}$ therefore differs from $\mathrm{CoO}_{\mathrm{x}}$ films that form from $\mathrm{Co}_{4} \mathrm{P}_{2} \mathrm{~W}_{18}$ and $\mathrm{Co}_{4} \mathrm{~V}_{2} \mathrm{~W}_{18}$ that do not contain tungsten $^{23,27}$ and from films formed from just $\mathrm{Co}(\mathrm{II})$. In short, using Co-POMs as a precatalyst for films that make Wcontaining $\mathrm{CoO}_{\mathrm{x}}$ films involves two (unintended) leached elements of the original Co-POM.

Next, 30 min electrolysis was conducted on $3 \mathrm{~h}$ aged solutions of $500 \mu \mathrm{M} \mathrm{Co}_{4} \mathrm{P}_{2} \mathrm{~W}_{18}$ in $0.1 \mathrm{M} \mathrm{NaPi}$ pH 8.0 with 10 equiv of EDTA/Co(II) $)_{a q}$ added after $3 \mathrm{~h}$ aging, but prior to electrolysis. The SEM and XPS of that particular electrode is presented in Figure 7 and confirms that heterogeneous $\mathrm{CoO}_{\mathrm{x}}$ does not form in the presence of excess EDTA from $3 \mathrm{~h}$ aged solutions of $500 \mu \mathrm{M} \mathrm{Co}_{4} \mathrm{P}_{2} \mathrm{~W}_{18}$ in $0.1 \mathrm{M} \mathrm{NaPi} \mathrm{pH} \mathrm{8.0.} \mathrm{This}$ finding provides further evidence that the Co-POM cannot form $\mathrm{CoO}_{\mathrm{x}}$ directly from, for example, putative electrodebound Co-POM. Instead, the $\mathrm{CoO}_{x}$ film observed when starting with the $\mathrm{Co}_{4} \mathrm{P}_{2} \mathrm{~W}_{18}$ precatalyst is formed by $\mathrm{Co}_{4} \mathrm{P}_{2} \mathrm{~W}_{18}$ releasing $\mathrm{Co}(\mathrm{II})_{\mathrm{aq}}$, consistent with hypothesis \#3 (i.e., and not \#4) from Scheme 1, vide supra.

Additional CV experiments using $3 \mathrm{~h}$ aged $500 \mu \mathrm{M} \alpha_{1^{-}}$ $\mathrm{CoP}_{2} \mathrm{~W}_{17}$ in $0.1 \mathrm{M} \mathrm{NaPi} \mathrm{pH} 5.8$ are discussed in the Supporting Information (Figures S15 and S16). The main results from those experiments using this more stable Co-POM is that although catalytic current increases, an electrode bound film is not formed from the bulk electrolysis of the Co-POM solution. 

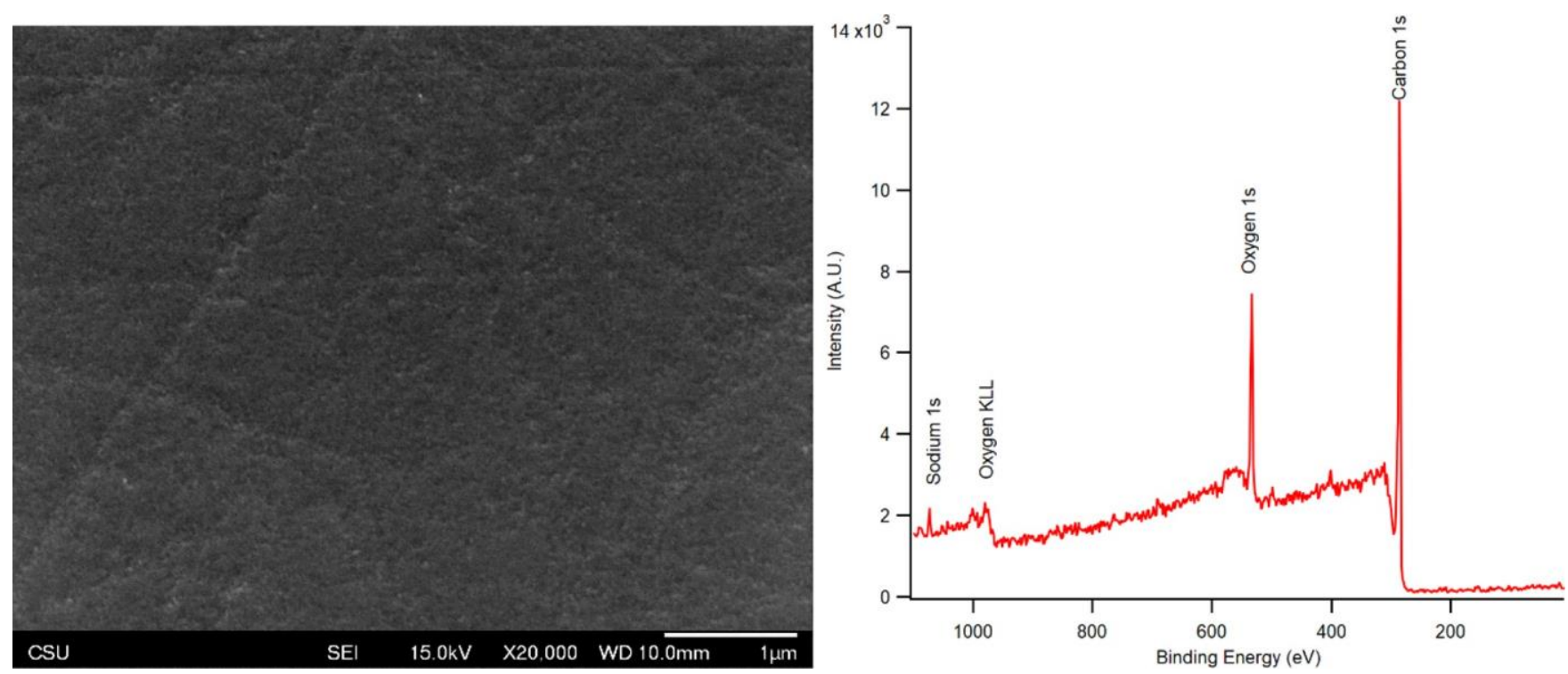

Figure 7. SEM micrograph (left) and XPS (right) of electrodes after 30 min bulk electrolysis from a $3 \mathrm{~h}$ aged solution of $500 \mu \mathrm{MCo}_{4} \mathrm{P}_{2} \mathrm{~W}_{18}$ in 0.1 $\mathrm{M} \mathrm{NaPi} \mathrm{pH} 8.0$ with $600 \mu \mathrm{M}$ EDTA(10 equiv/Co(II) $)_{\mathrm{aq}}$ ). The i vs t curve for the film deposition is presented in Figure S14 of the Supporting Information.

To summarize the experiments on the electrochemical and morphological characterization of the deposited films, under conditions where the Co-POMs show >2\% detectable $\mathrm{Co}(\mathrm{II})_{\mathrm{aq}}, \mathrm{CoO}_{\mathrm{x}}$ is formed and that film accounts quantitatively for the observed WOCatalysis (Table 2, Figure 3, and Figures S13 and S16 of the Supporting Information). However, under conditions where the Co-POMs are more stable $(<2 \%$ detectable $\mathrm{Co}(\mathrm{II})_{\mathrm{aq}}$ ) such as with $\mathrm{\alpha}_{1}-\mathrm{CoP}_{2} \mathrm{~W}_{17}$, no detectable electrode-bound $\mathrm{CoO}_{\mathrm{x}}$ is seen. Rather, a solution-based species is responsible for the observed WOCatalysis current (Table 2, Figures 5, and Figures S13 and S15 of the Supporting Information), again and ostensibly the starting Co-POM at the Ockham's razor level of interpretation. Lastly, addition of a 10fold excess of EDTA (vs the amount of free $\mathrm{Co}(\mathrm{II})_{\mathrm{aq}}$ detected) prevents the formation of $\mathrm{CoO}_{\mathrm{x}}$, at least with $3 \mathrm{~h}$ aged solution of $500 \mu \mathrm{M} \mathrm{Co}_{4} \mathrm{P}_{2} \mathrm{~W}_{18}$ in $0.1 \mathrm{M} \mathrm{NaPi} \mathrm{pH} 8.0$ (Figure 7). This, too, is evidence that $\mathrm{CoO}_{\mathrm{x}}$ is formed from $\mathrm{Co}(\mathrm{II})_{\mathrm{aq}}$ and not from intact, electrode-bound Co-POM.

\section{SUMMARY AND CONCLUSIONS}

The present study details the broadest and most quantitative, micromolar-level examination to date of the stability and electrochemically driven WOCatalysis from Co-POM precatalysts. Six exemplary Co-POMs $\left[\mathrm{Co}_{4}\left(\mathrm{H}_{2} \mathrm{O}\right)_{2}\left(\mathrm{PW}_{9} \mathrm{O}_{34}\right)_{2}\right]^{10-}$ $\left(\mathrm{Co}_{4} \mathrm{P}_{2} \mathrm{~W}_{18}\right), \quad\left[\beta, \beta-\mathrm{Co}_{4}\left(\mathrm{H}_{2} \mathrm{O}\right)_{2}\left(\mathrm{P}_{2} \mathrm{~W}_{15} \mathrm{O}_{56}\right)_{2}\right]^{16-}\left(\mathrm{Co}_{4} \mathrm{P}_{4} \mathrm{~W}_{30}\right)$, $\left[\mathrm{Co}_{9}\left(\mathrm{H}_{2} \mathrm{O}\right)_{6}(\mathrm{OH})_{3}\left(\mathrm{HPO}_{4}\right)_{2}\left(\mathrm{PW}_{9} \mathrm{O}_{34}\right)_{3}\right]^{16-}\left(\mathrm{Co}_{9} \mathrm{P}_{5} \mathrm{~W}_{27}\right),[\mathrm{Co}-$ $\left.\left(\mathrm{H}_{2} \mathrm{O}\right) \mathrm{PW}_{11} \mathrm{O}_{39}\right]^{5-}\left(\mathrm{CoPW}_{11}\right),\left[\mathrm{a}_{1}-\mathrm{Co}\left(\mathrm{H}_{2} \mathrm{O}\right) \mathrm{P}_{2} \mathrm{~W}_{17} \mathrm{O}_{61}\right]^{8-}$ $\left(\alpha_{1}-\mathrm{CoP}_{2} \mathrm{~W}_{17}\right)$, and $\left[\alpha_{2}-\mathrm{Co}\left(\mathrm{H}_{2} \mathrm{O}\right) \mathrm{P}_{2} \mathrm{~W}_{17} \mathrm{O}_{61}\right]^{8-}\left(\alpha_{2-}\right.$ $\left.\mathrm{CoP}_{2} \mathrm{~W}_{17}\right)$ were synthesized, their structural integrity established, and then their stability and electrochemically driven WOCatalysis examined under $\mathrm{pH}$ 5.8, 8.0, and 9.0 buffer conditions chosen from the literature. Importantly, the amount of $\mathrm{Co}(\mathrm{II})_{\mathrm{aq}}$ leached from the Co-POMs into solution was quantified directly, at the $\mu \mathrm{M}$-level, using $\mathrm{Co}(\mathrm{II})_{\mathrm{aq}}$-induced line broadening of the ${ }^{31} \mathrm{P}$ NMR resonance of phosphate buffer at $\mathrm{pH} 5.8$ and 8.0, and by cathodic stripping in the case of $\mathrm{pH} 9.0$ borate buffer. The WOCatalysis activity derived from the CoPOM precatalysts was then compared with the WOCatalysis activity of the equivalent amount of $\mathrm{Co}(\mathrm{II})_{\mathrm{aq}}$ present in solution from each of the Co-POMs.

The main conclusions from this study are the following:

- Significantly, $\mathrm{Co}(\mathrm{II})_{\mathrm{aq}}$ at the micromolar or higher level was detected for every Co-POM under each set of $\mathrm{pH}$ and buffer conditions. The amount of detectable $\mathrm{Co}(\mathrm{II})_{\mathrm{aq}}$ as a percentage of the total cobalt present in each Co-POM varies from $\sim 0.25 \%$ to $50 \%$ (and up to $90 \%$ in borate buffer at $\mathrm{pH} 9$ ) of the total $\mathrm{Co}(\mathrm{II})$ after 3 $\mathrm{h}$ in solution, the precise amount being unique to the POM structure/Co(II) binding site and notably the $\mathrm{pH}$ and buffer, higher $\mathrm{pH}$ values and phosphate buffer in general leading to higher levels of $\mathrm{Co}(\mathrm{II})_{\mathrm{aq}}$ (Figure 2 and Table 1, vide supra).

- In the case of Co-POMs with high anionic charge such as $\left[\beta, \beta-\mathrm{Co}_{4}\left(\mathrm{H}_{2} \mathrm{O}\right)_{2}\left(\mathrm{P}_{2} \mathrm{~W}_{15} \mathrm{O}_{56}\right)_{2}\right]^{16-}\left(\mathrm{Co}_{4} \mathrm{P}_{4} \mathrm{~W}_{30}\right)$, $\mathrm{Co}(\mathrm{II})$ can be present as a countercation impurity-a likely more general phenomenon for $\mathrm{M}^{\mathrm{n}+}$ ions used in the synthesis of $\mathrm{M}^{\mathrm{n}+}$-POMs. While ion-exchange resin, recrystallization from counterion-controlled solutions, or other countercation control efforts may be able to remove such countercation impurities, that remains to be demonstrated by $\leq$ micromolar-sensitive methods such as those employed herein.

- In 12 out of the 18 Co-POM cases at pH 8.0 and 9.0 in Table 2, the amount of heterogeneous $\mathrm{CoO}_{x}$ generated from the detected $\mathrm{Co}(\mathrm{II})_{\mathrm{aq}}$ accounts for $\geq 100 \%$ of the observed activity-meaning that under those higher $\mathrm{pH}$ conditions the kinetically dominant, electrochemically driven WOCatalyst is heterogeneous $\mathrm{CoO}_{\mathrm{x}}$. In those cases, using simple $\mathrm{Co}$ (II) salts to prepare the resultant, high-activity $\mathrm{CoO}_{x}$ would be a far easier, greener, and overall better use of chemicals, time, and synthetic effort.

- In terms of catalytic rate, at $\mathrm{pH} 8.0$ and for the single most stable Co-POM, $\alpha_{1}-\mathrm{CoP}_{2} \mathrm{~W}_{17}$, the $\mathrm{CoO}_{\mathrm{x}}$ catalyst formed from $\mathrm{Co}(\mathrm{II})_{\mathrm{aq}}$ is an estimated at least 80 -fold if not $\sim 740$-fold more active than any (undetectable) CoPOM based WOC. As an illustrative example, this means that (using the 740 -fold value) even $\sim 0.14 \%$ of 
decomposition of $\alpha_{1}-\mathrm{CoP}_{2} \mathrm{~W}_{17}$ to $\mathrm{Co}(\mathrm{II})_{\mathrm{aq}}$ would be able in turn, at $\mathrm{pH}=8.0$, to carry $\geq 99 \%$ of the catalytic WOCatalysis current. Put in other words, finding the kinetically dominant true WOCatalyst when starting with $500 \mathrm{mM}$ Co-POMs is a $\mu \mathrm{M}$ detection and detective problem.

- However, under pH 5.8 conditions where the Co-POMs are generally more stable, the amount of $\mathrm{Co}(\mathrm{II})_{\mathrm{aq}}$ detected cannot account for the observed WOCatalysis. Specifically, for $\mathrm{CoPW}_{11}$ and $\alpha_{1}-\mathrm{CoP}_{2} \mathrm{~W}_{17}$ at $\mathrm{pH} 5.8$ where $\sim 1.3 \%$ and $\sim 0.25 \%$ detectable $\mathrm{Co}(\mathrm{II})_{\mathrm{aq}}$ are seen, respectively, $80( \pm 20 \%)$ and $84 \%( \pm 6 \%)$ of the observed WOCatalysis activity can be ascribed (in the Ockham's razor interpretation) to molecular, Co-POM-based catalysis, Table 2, vide supra. That said, the Co-POMbased WOCatalysis rate is still an estimated $\sim 35$ to 150 fold slower than that for an equivalent amount of $\mathrm{CoO}_{x}$ for even the most stable Co-POM examined, $\alpha_{1^{-}}$ $\mathrm{CoP}_{2} \mathrm{~W}_{17}$.

- In general, our findings confirm and fully support those of prior workers who have concluded that the reaction conditions are important in determining the identity of the kinetically dominant WOCatalyst derived from CoPOMs. ${ }^{17,24-27}$ We emphasize here that all of our experiments were deliberately conducted under electrochemical conditions; the nature of the true WOCatalysts under chemical or photochemical oxidation (e.g., using $\mathrm{Ru}(\mathrm{III}) \mathrm{bpy}_{3}{ }^{3+}$ or $\mathrm{Ru}(\mathrm{II}) \mathrm{bpy}_{3}{ }^{2+}+\mathrm{hv}$ ) will likely be different under those (different) conditions. That said, the method of multiple alternative hypotheses, particularly those listed in Scheme 1, are expected to prove useful to future researchers striving to determine experimentally the true, kinetically dominant WOCatalyst under their own oxidant, $\mathrm{pH}$, buffer, and other specific conditions.

- A summary of additional POMs used in WOCatalysis which are not discussed in the main text, yet merit further study as to the identity of the true catalyst, are presented in Table S1 of the Supporting Information for the interested reader.

Finally and overall, the results obtained and presented herein in combination with prior notable work from others in the field of electrocatalytic WOCatalysis ${ }^{7,13,17,23-27}$ suggest that even more hydrolytically stable Co-POM and other Metal-POM WOCatalysts merit further development. The combined results also illustrate a successful, arguably preferred methodology for distinguishing molecular homogeneous from metal oxide heterogeneous WOCatalysts, even when metal-leaching or countercation contamination is present at just micromolar levels. It is hoped that these efforts will allow even more stable and active Co-POM based WOCatalysts to be developed, studies also hopefully now able to report compelling evidence for or against molecular, Co-POM-based vs heterogeneous, $\mathrm{CoO}_{\mathrm{x}}$-based WOCatalysis.

\section{ASSOCIATED CONTENT}

Supporting Information

The Supporting Information is available free of charge on the ACS Publications website at DOI: 10.1021/jacs.8b06303.

Tables S1 and S2, Figures S1-S16, and a brief discussion of the error bars in Table 2 (PDF)

\section{AUTHOR INFORMATION}

Corresponding Author

*richard.finke@colostate.edu

ORCID

Jose Ramon Galan-Mascaros: 0000-0001-7983-9762

Richard G. Finke: 0000-0002-3668-7903

Present Address

§Present address: School of Chemistry and CRANN/AMBER

Nanoscience Institute, Trinity College, College Green, Dublin 2, Ireland.

Notes

The authors declare no competing financial interest.

\section{ACKNOWLEDGMENTS}

Funding from NSF Grant Nos. CHE-1361515 and 1664646 is gratefully acknowledged. It is also a pleasure to acknowledge discussions and cooperation with Professor Craig Hill and his research group, discussions and a cooperation which have helped highlight the issues and complexities in establishing the true catalyst in Co-POM precatalyst-based WOCatalysis. Finally, Dr. Jordan Stracke is thanked for early thoughts about this project, and for preparing the sample of $\mathrm{Co}_{4} \mathrm{P}_{2} \mathrm{~W}_{18}$ used herein.

\section{REFERENCES}

(1) Turner, J. A. Science 1999, 285, 687-689.

(2) Lewis, N. S.; Nocera, D. G. Proc. Natl. Acad. Sci. U. S. A. 2006,

103, 15729-15735.

(3) Karkas, M.; Åkermark, B. Dalton Trans 2016, 45, 14421-14461.

(4) Llobet, A. Molecular Water Oxidation Catalysis, 1 ed..; Wiley, 2014.

(5) Liu, F.; Concepcion, J. J.; Jurss, J. W.; Cardolaccia, T.; Templeton, J. L.; Meyer, T. J. Inorg. Chem. 2008, 47, 1727-1752. (6) Geletii, Y. V.; Botar, B.; Kögerler, P.; Hillesheim, D. A.; Musaev, D. G.; Hill, C. L. Angew. Chem., Int. Ed. 2008, 47, 3896-3899.

(7) Sartorel, A.; Carraro, M.; Scorrano, G.; Zorzi, R. D.; Geremia, S.; McDaniel, N. D.; Bernhard, S.; Bonchio, M. J. Am. Chem. Soc. 2008, 130, 5006-5007.

(8) Kanan, M. W.; Nocera, D. G. Science 2008, 321, 1072-1075.

(9) Yin, Q.; Tan, J. M.; Besson, C.; Geletii, Y. V.; Musaev, D. G.; Kuznetsov, A. E.; Luo, Z.; Hardcastle, K. I.; Hill, C. L. Science 2010, 328, 342-345.

(10) Huang, Z.; Luo, Z.; Geletii, Y. V.; Vickers, J. W.; Yin, Q.; Wu, D.; Hou, Y.; Ding, Y.; Song, J.; Musaev, D. G.; Hill, C. L.; Lian, T. J. Am. Chem. Soc. 2011, 133, 2068-2071.

(11) Zhu, G.; Geletii, Y. V.; Kögerler, P.; Schilder, H.; Song, J.; Lense, S.; Zhao, C.; Hardcastle, K. I.; Musaev, D. G.; Hill, C. L. Dalton Trans 2012, 41, 2084.

(12) Zhu, G.; Glass, E. N.; Zhao, C.; Lv, H.; Vickers, J. W.; Geletii, Y. V.; Musaev, D. G.; Song, J.; Hill, C. L. Dalton Trans 2012, 41, 13043-13049.

(13) Goberna-Ferron, S.; Vigara, L.; Soriano-Lopez, J.; GalanMascaros, J. R. Inorg. Chem. 2012, 51, 11707-11715.

(14) Car, P.-E.; Guttentag, M.; Baldridge, K. K.; Alberto, R.; Patzke, G. R. Green Chem. 2012, 14, 1680.

(15) Evangelisti, F.; Car, P.-E.; Blacque, O.; Patzke, G. R. Catal. Sci. Technol. 2013, 3, 3117.

(16) Lv, H.; Song, J.; Geletii, Y. V.; Vickers, J. W.; Sumliner, J. M.; Musaev, D. G.; Kogerler, P.; Zhuk, P. F.; Bacsa, J.; Zhu, G.; Hill, C. L. J. Am. Chem. Soc. 2014, 136, 9268-9271.

(17) Vickers, J. W.; Lv, H.; Sumliner, J. M.; Zhu, G.; Luo, Z.; Musaev, D. G.; Geletii, Y. V.; Hill, C. L. J. Am. Chem. Soc. 2013, 135 (38), 14110-14118.

(18) Pope, M. T. Heteropoly and Isopoly Oxometalates; SpringerVerlag, 1983. 
(19) Yamase, T.; Pope, M. Polyoxometalate Chemistry for NanoComposite Design; Springer Science \& Business Media, 2006.

(20) Pope, M.; Muller, A. Polyoxometalates: From Platonic Solids to Anti-Retroviral Activity: From Platonic Solids to Anti-Retroviral Activity; Springer Science \& Business Media, 1994.

(21) Contant, R.; Ciabrini, J.-P. J. Chem. Res. 1982, 50-51.

(22) Contant, R. J. Chem. Res. 1984, 120-121.

(23) Stracke, J. J.; Finke, R. G. J. Am. Chem. Soc. 2011, 133, $14872-$ 14875 .

(24) Stracke, J. J.; Finke, R. G. ACS Catal. 2013, 3, 1209-1219.

(25) Stracke, J. J.; Finke, R. G. ACS Catal. 2014, 4, 909-933.

(26) Stracke, J. J.; Finke, R. G. ACS Catal. 2014, 4 (1), 79-89.

(27) Folkman, S. J.; Finke, R. G. ACS Catal. 2017, 7, 7-16.

(28) Ullman, A. M.; Liu, Y.; Huynh, M.; Bediako, D. K.; Wang, H.; Anderson, B. L.; Powers, D. C.; Breen, J. J.; Abruña, H. D.; Nocera, D.

G. J. Am. Chem. Soc. 2014, 136 (50), 17681-17688.

(29) Platt, J. R. Science 1964, 146 (3642), 347-353.

(30) Weakley, T. J. R. J. Chem. Soc., Chem. Commun. 1984, 21, 1406-1407.

(31) Galan-Mascaros, J. R.; Gomez-Garcia, C. J.; Borras-Almenar, J. J.; Coronado, E. Adv. Mater. 1994, 6 (3), 221-223.

(32) Soriano-Lopez, J.; Goberna-Ferron, S.; Vigara, L.; Carbó, J. J.; Poblet, J. M.; Galan-Mascaros, J. R. Inorg. Chem. 2013, 52 (9), 47534755.

(33) Blasco-Ahicart, M.; Soriano-Lopez, J.; Carbó, J. J.; Poblet, J. M.; Galan-Mascaros, J. R. Nat. Chem. 2018, 10 (1), 24-30.

(34) Darensbourg, M. Inorganic Syntheses; John Wiley \& Sons, 1998; Vol. 32, pp 175-182.

(35) Ruhlmann, L.; Costa-Coquelard, C.; Canny, J.; Thouvenot, R. Eur. J. Inorg. Chem. 2007, 2007, 1493-1500.

(36) Bailar, J. C.; Booth, H. S.; Grennert, M. Phosphotungstic Acid. In Inorganic Syntheses; Booth, H. S., Ed.; John Wiley \& Sons, Inc., 1939; pp 132-133.

(37) Weakley, T. J. R.; Malik, S. A. J. Inorg. Nucl. Chem. 1967, 29, 2935-2944.

(38) Tourne', C. M.; Tourne', G. F.; Malik, S. A.; Weakley, T. J. R. J. Inorg. Nucl. Chem. 1970, 32, 3875-3890.

(39) Jorris, T. L.; Kozik, M.; Casan-Pastor, N.; Domaille, P. J.; Finke, R. G.; Miller, W. K.; Baker, L. C. W. J. Am. Chem. Soc. 1987, 109, 7402-7408.

(40) Li, J.; Wang, J.; Zhang, L.; Sang, X.; You, W. J. Coord. Chem. 2017, 70, 2950-2957.

(41) Contant, R.; Klemperer, W. G.; Yaghi, O. Potassium Octadecatungstodiphosphates(V) and Related Lacunary Compounds. Inorganic Syntheses; Ginsberg, A. P., Ed.; John Wiley \& Sons, Inc., 1990; pp 104-111.

(42) Samonte, J. L.; Pope, M. T. Can. J. Chem. 2001, 79, 802-808.

(43) Lyon, D. K.; Miller, W. K.; Novet, T.; Domaille, P. J.; Evitt, E.; Johnson, D. C.; Finke, R. G. J. Am. Chem. Soc. 1991, 113, 7209-7221.

(44) Barats-Damatov, D.; Shimon, L. J. W.; Weiner, L.; Schreiber, R. E.; Jimenez-Lozano, P.; Poblet, J. M.; de Graaf, C.; Neumann, R. Inorg. Chem. 2014, 53 (3), 1779-1787.

(45) Haynes, W. M.; Lide, D. R. Handbook of Chemistry and Physics,

92nd ed.; Taylor and Francis Group, 2011.

(46) Klanberg, F.; Hunt, J. P.; Dodgen, H. W. Naturwissenschaften 1963, 50 (3), 90-91.

(47) Surendranath, Y.; Lutterman, D. A.; Liu, Y.; Nocera, D. G. J. Am. Chem. Soc. 2012, 134 (14), 6326-6336.

(48) Bazzan, I.; Volpe, A.; Dolbecq, A.; Natali, M.; Sartorel, A.; Mialane, P.; Bonchio, M. Catal. Today 2017, 290, 39-50.

(49) Krolicka, A.; Bobrowski, A.; Kalcher, K.; Mocak, J.; Svancara, I.; Vytras, K. Electroanalysis 2003, 15 (23-24), 1859-1863.

(50) Widegren, J. A.; Finke, R. G. J. Mol. Catal. A: Chem. 2003, 198 (1), 317-341.

(51) Kirner, J. T.; Stracke, J. J.; Gregg, B. A.; Finke, R. G. ACS Appl. Mater. Interfaces 2014, 6 (16), 13367-13377.

(52) Finke, R. G.; Droege, M.; Hutchinson, J. R.; Gansow, O. J. Am. Chem. Soc. 1981, 103 (6), 1587-1589.
(53) Folkman, S. J.; Kirner, J. T.; Finke, R. G. Inorg. Chem. 2016, 55 (11), 5343-5355.

(54) Baes, C.; Mesmer, R. The Hydrolysis of Cations; John Wiley \& Sons, 1976.

(55) Finke, R. G.; Droege, M. W.; Domaille, P. J. Inorg. Chem. 1987, 26 (23), 3886-3896.

(56) Ruhlmann, L.; Nadjo, L.; Canny, J.; Contant, R.; Thouvenot, R. Eur. J. Inorg. Chem. 2002, 2002, 975-986.

(57) Gerken, J. B.; McAlpin, J. G.; Chen, J. Y. C.; Rigsby, M. L.; Casey, W. H.; Britt, R. D.; Stahl, S. S. J. Am. Chem. Soc. 2011, 133 (36), 14431-14442.

(58) Zhang, B.; Wu, X.; Li, F.; Yu, F.; Wang, Y.; Sun, L. Chem. Asian J. 2015, 10, 2228-2233. 